\title{
Learning About Assessment: An Evaluation of a Ten-State Effort to Build Assessment Capacity in High Schools
}

Elliot H. Weinbaum

University of Pennsylvania

Follow this and additional works at: https://repository.upenn.edu/cpre_researchreports

Part of the Curriculum and Instruction Commons, Educational Assessment, Evaluation, and Research Commons, Educational Methods Commons, Education Policy Commons, and the Teacher Education and Professional Development Commons

\section{Recommended Citation}

Weinbaum, Elliot H.. (2009). Learning About Assessment: An Evaluation of a Ten-State Effort to Build Assessment Capacity in High Schools. CPRE Research Reports.

Retrieved from https://repository.upenn.edu/cpre_researchreports/52

View on the CPRE website.

This paper is posted at ScholarlyCommons. https://repository.upenn.edu/cpre_researchreports/52

For more information, please contact repository@pobox.upenn.edu. 


\title{
Learning About Assessment: An Evaluation of a Ten-State Effort to Build Assessment Capacity in High Schools
}

\author{
Abstract \\ In 2006, the State of Delaware and the Council of Chief State School Officers (CCSSO) partnered with the \\ Consortium for Policy Research in Education (CPRE) to conduct an evaluation of a ten-state initiative that \\ sought to enhance assessment practices at the high school level. This effort aimed to help states, \\ districts, and schools build familiarity with instruction that uses assessment as part of the learning \\ process, a practice known as assessment for learning. This report focuses primarily on the third goal of \\ this project, the creation and function of teacher learning teams focused on assessment for learning. \\ Disciplines \\ Curriculum and Instruction | Educational Assessment, Evaluation, and Research | Educational Methods | \\ Education Policy I Teacher Education and Professional Development

\section{Comments} \\ View on the CPRE website.
}




\title{
Learning About Assessment
}

An Evaluation of a Ten-State

\section{Effort to Build Assessment}

Capacity in High Schools

Elliot H. Weinbaum

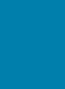

PRE

Consortium for Policy Research in Education

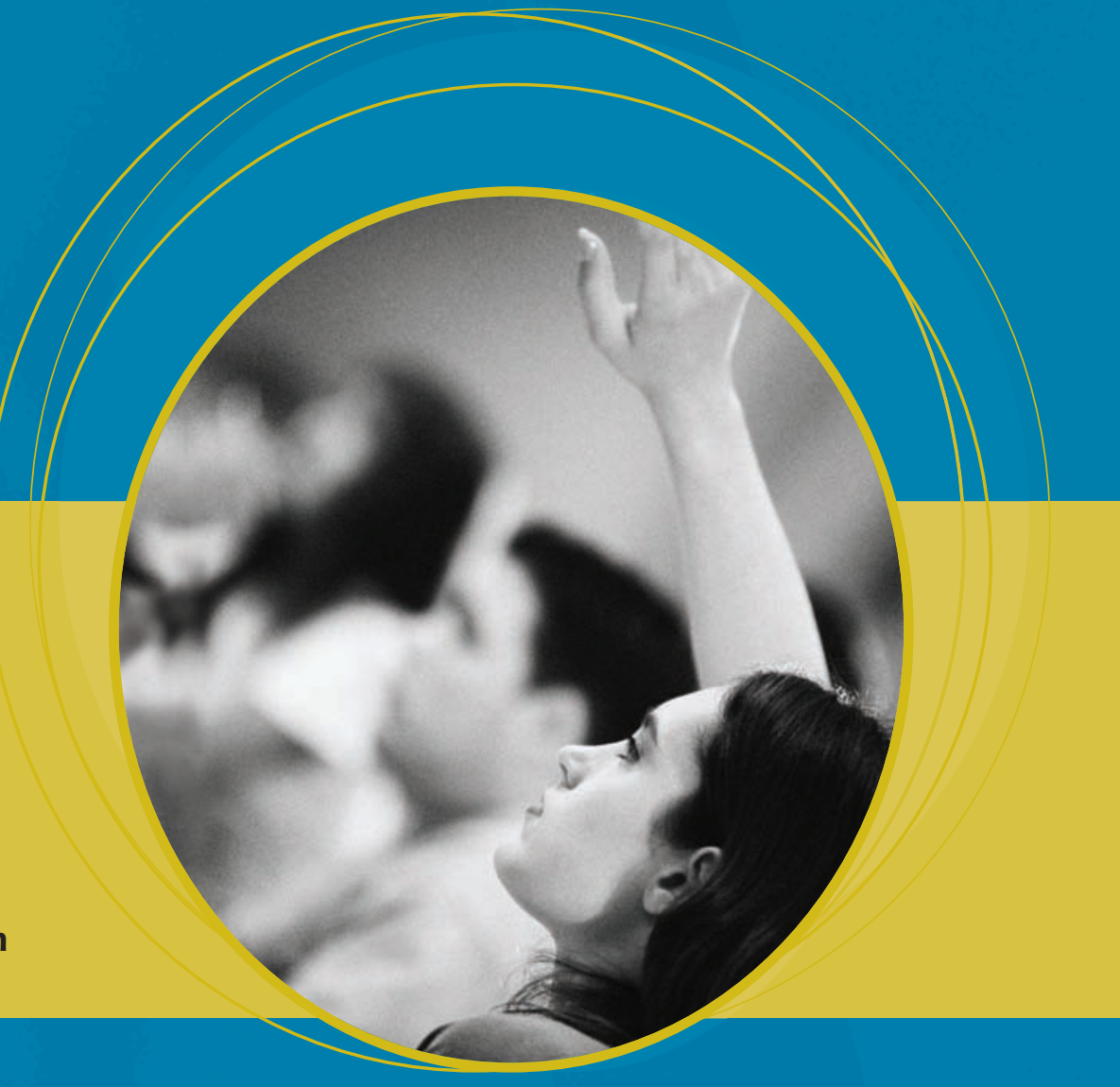

University of Pennsylvania

Teachers College Columbia University

Harvard University

Stanford University

University of Michigan

University of Wisconsin-Madison

Northwestern University 


\section{About the Consortium for Policy Research in Education}

The Consortium for Policy Research in Education (CPRE) unites seven of the nation's top research institutions in an exciting venture to improve student learning through research on policy, finance, school reform, and school governance. The members of CPRE are the University of Pennsylvania, Teachers College Columbia University, Harvard University, Stanford University, the University of Michigan, the University of Wisconsin-Madison, and Northwestern University. CPRE is currently examining how alternative approaches to reform - such as new accountability policies, teacher compensation, whole-school reform approaches, and efforts to contract out instructional services-address issues of coherence, incentives, and capacity.

To learn more about CPRE, visit our website at www.cpre.org or call 215-573-0700. CPRE Research Reports are issued by CPRE to facilitate the exchange of ideas among policymakers, practitioners, and researchers who share an interest in education policy. The views expressed in the reports are those of individual authors and are not necessarily shared by CPRE or its institutional partners. 


\section{Learning About Assessment}

\section{An Evaluation of a Ten-State}

\section{Effort to Build Assessment}

Capacity in High Schools

Elliot H. Weinbaum

\section{QPRE}

Consortium for Policy Research in Education

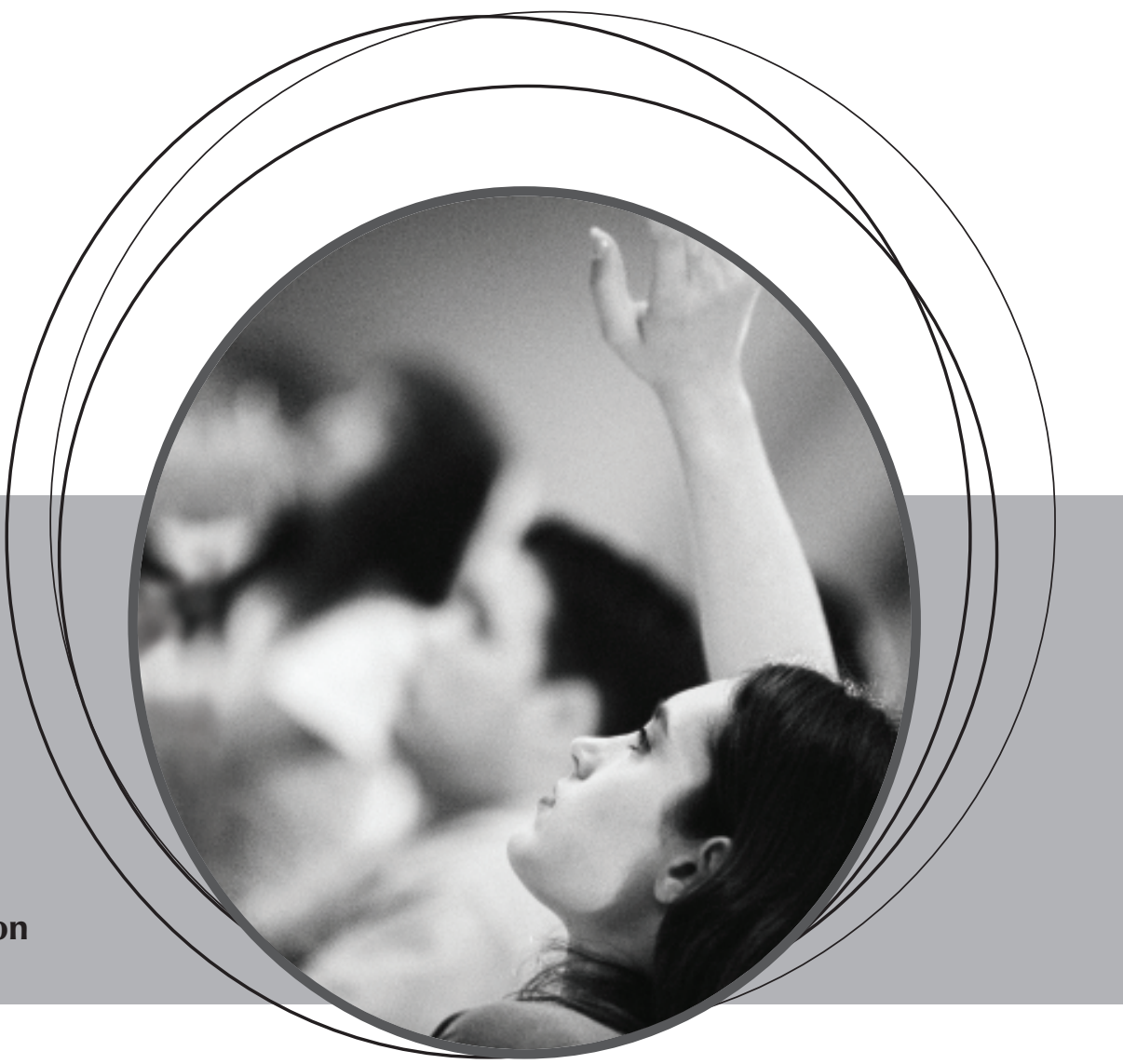

This research was funded through a subcontract with the Council of Chief State School Officers (CCSSO), under a U.S. Department of Education grant (\#S368A060011) to the Delaware Department of Education. The views represented in this report do not necessarily reflect those of CCSSO, the U.S. Department of Education, the Delaware Department of Education, or the prime provider of program materials (Educational Testing Service).

\section{February 2009}




\section{Acknowledgments}

This report could not have been written without goodwill, patience, advice, guidance and input from countless people involved in this project. State leadership teams in all ten of the participating states and high school staffs in the five focal high schools were most important in providing insight into their experiences as they tried to incorporate assessment for learning in countless classrooms around the United States. Though they remain anonymous, I hope that they can see their own experiences reflected accurately in this document. I would also like to thank the team that led the implementation of this project, providing me with access to a fascinating effort to document and study. The leadership team included Rolf Blank, Stephen Chappuis, Jim Hertzog, Wendy Roberts Pickett, Doris Redfield, Douglas Rindone, and Richard Stiggins. I would also like to thank Mary Kennedy, Nell Scharff and Margaret Goertz for their thorough and thoughtful reviews of earlier drafts of this work. Any inaccuracies that remain in this report are entirely my own. 


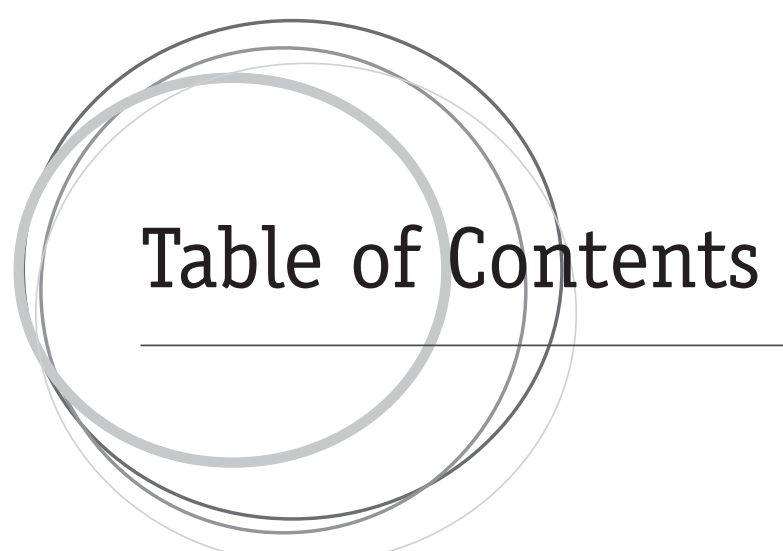

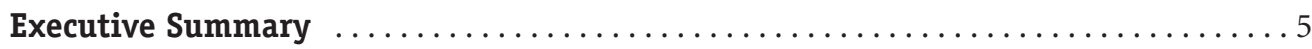

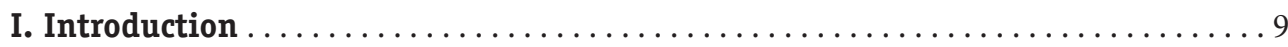

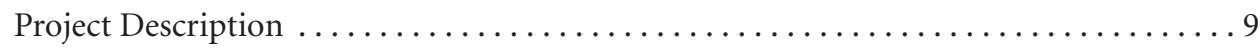

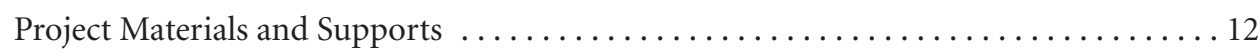

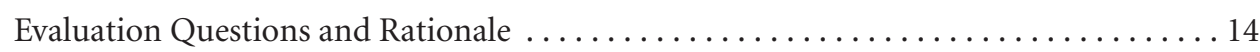

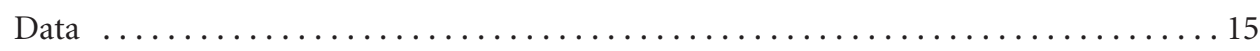

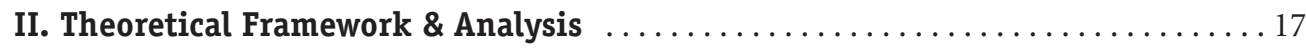

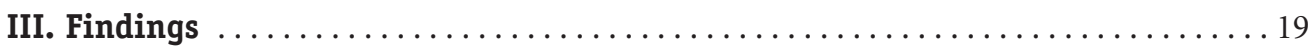

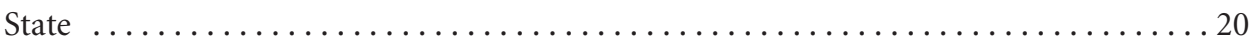

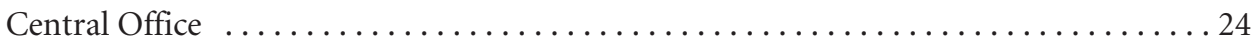

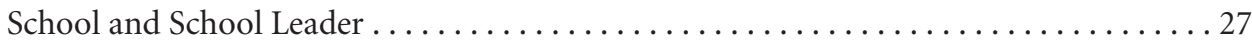

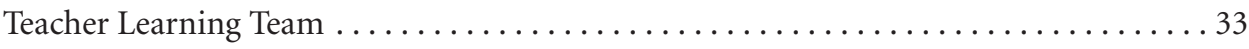

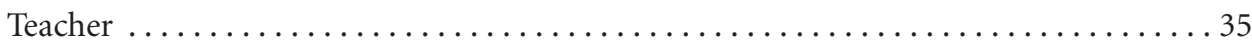

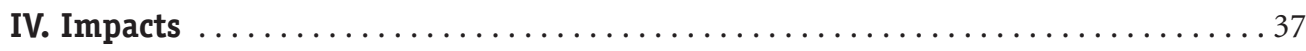

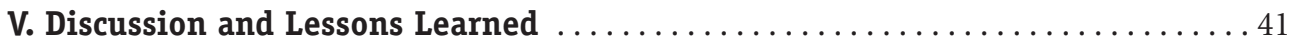

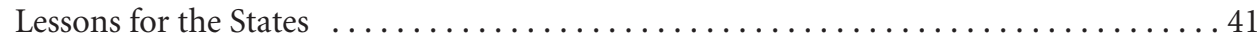

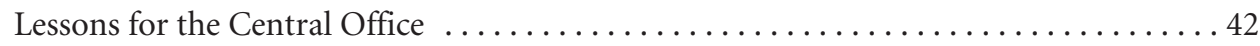

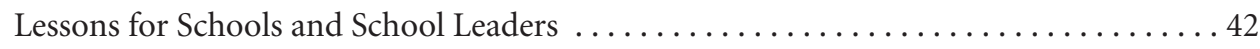

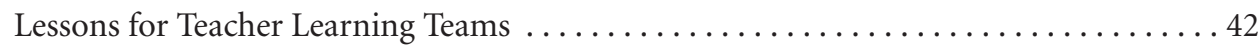

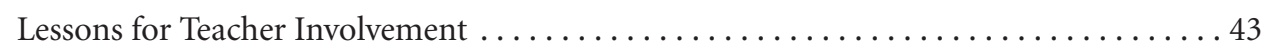

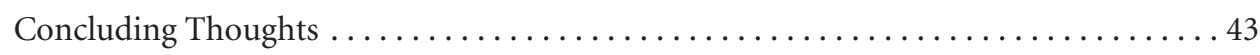

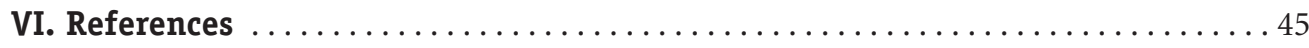

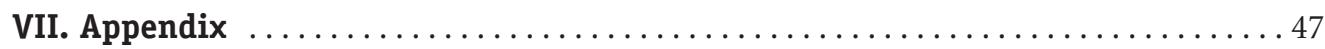




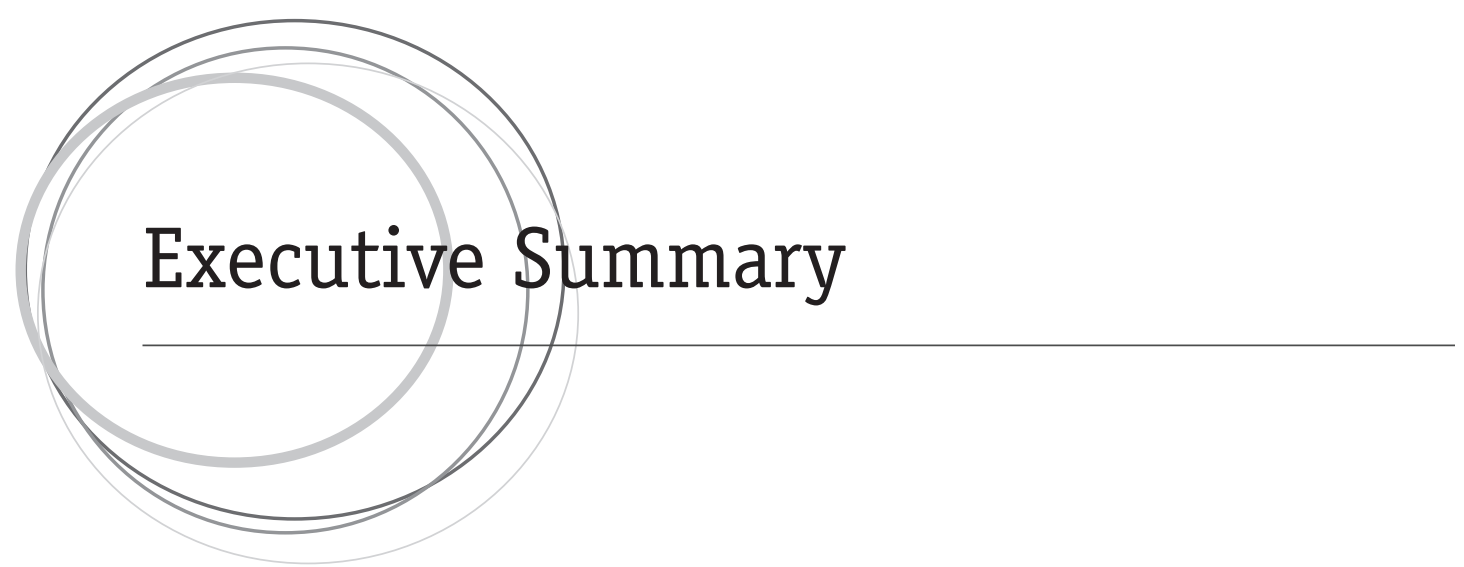

In 2006, the State of Delaware and the Council of Chief State School Officers (CCSSO) partnered with the Consortium for Policy Research in Education (CPRE) to conduct an evaluation of a ten-state initiative that sought to enhance assessment practices at the high school level. This effort aimed to help states, districts, and schools build familiarity with instruction that uses assessment as part of the learning process, a practice known as assessment for learning.

The initial design of the project had four goals:

Goal 1: Develop and implement a practitioner- and research-based vision of a comprehensive and balanced assessment system.

Goal 2: Build state leadership capacity and support each state's technical assistance to districts and high schools in providing high-quality professional and leadership development in balanced assessment systems and specific practices of assessment for learning.

Goal 3: Have district/high school teams begin to implement a vision of assessment for learning in schools and classrooms.

Goal 4: Generate and disseminate tools, techniques, and new knowledge to support future approaches to teaching and learning, while strengthening the commitment to all students learning at higher levels.

This report focuses primarily on the third goal of this project, the creation and function of teacher learning teams focused on assessment for learning. The materials used to assist in achieving this goal were designed by the Assessment Training Institute, a division of the Educational Testing Service (ETS). Leaders at the state, district, and school levels relied heavily on one particular ETS text, Classroom Assessment for Student Learning, for guidance about implementing assessment for learning in classroom settings. Other support included interactive Internet meetings, consultations with the ETS developers, a Web-based discussion board, and two national meetings.

The CPRE evaluation relied on (1) observation of trainings and meetings, (2) interviews with leadership in all 10 participating states, (3) interviews with teachers and school leaders in five high schools in two states, and (4) surveys of teaching staff in those schools. Seventy interviews were conducted with 43 teachers and leaders at the five schools in the spring and fall of 2007 and again in the spring of 2008. In total, 100 interviews were conducted with 65 individuals. CPRE research staff also observed the two state team training sessions as well as trainings for school staff in both states. 


\section{Program Implementation}

The implementation of the assessment for learning strategies in the schools took longer than program leaders anticipated. Over the course of the first full school year in which teachers were expected to be working with the project materials, we found that in the five focal high schools: (1) learning teams struggled to meet on a regular basis; (2) program materials and resources were used in limited ways; (3) discussion or evidence of any change in classroom practice did not come until the spring; and (4) school teams frequently remained somewhat unclear about the intended "outcome."

\section{State Role}

States confronted a number of unanticipated challenges including difficulties with recruitment, lack of familiarity with the program material, and development of a new type of state-school relationship. Though roles for state leadership teams varied at the start, as their experience with the program progressed, states increasingly saw themselves as the essential element in moving the teams forward in their work. Their leadership was required to maintain a focus on the effort.

Some of the initially slow start to the project can be explained by the fact that participating teachers generally felt that the introductory meetings held by state leaders were quite vague and did not provide them with sufficient detail about the mission or goals of the grant project. Reflecting the lack of familiarity among program leaders and participants, teachers wanted to feel that they had experts to turn to when they had questions about the materials. Teachers also felt that they were getting mixed messages from the state. Finally, many teachers reported that they did not get a great deal of recognition or support from states

\section{Central Office Role}

Central office activity in this project was very limited. As a result, teachers expressed feeling conflicting priorities between ongoing district initiatives and this pilot program. Teachers also felt pressure from district leaders to move through course material at a predetermined pace, a practice that did not always align well with the new practices that teachers were learning through their participation in this program. Finally, some districts had systems (e.g., Internetbased grading systems, benchmark testing) with which teachers must comply. Like the pacing guides, these systems did not always align well with the new information and practices that teachers were learning.

\section{School and School Leader Role}

Some of the issues that implementing teachers identified at the district level also surfaced, though in slightly different ways, at the school level. Like districts, schools too were trying to institute particular initiatives that may or may not have aligned well with this pilot effort. Also, as all of the participating high schools had a history of low state test performance, school leaders exerted strong pressure to demonstrate improved performance on the state assessment. It was not always clear to teachers how to negotiate the competing demands placed on them and their practice.

Teachers reported that they struggled with this program because they felt like (and were) a minority in their schools and could not always advocate for the larger changes that would have been needed to implement the changes they were learning about. Being in a relatively small group with similar levels of experience, teachers did not feel as if they or anyone else in the 
school really had the expertise to be facilitating discussions about classroom assessment issues. Developing significant expertise took a great deal of time that was not always available to teachers or school leaders.

\section{Teacher and Learning Team Role}

The composition of the team posed at least six challenges for participating teachers:

1) Finding a common language to talk with peers: Teachers and teams struggled to negotiate a balance between interdisciplinary teams and discussion of subject-specific strategies to use in the classroom.

2) Changing the traditional functions of teams: When used with pre-existing teams, it was difficult to change the norms and functions of those teams.

3) Facilitating rich discussion: Responsibility for and knowledge of facilitation was not initially clear to teachers.

4) Changing the focus from teachers to students: Teams tended to focus on individual students rather than teachers' instructional strategies.

5) Dealing with teacher turnover: High turnover among teaching staffs in some high schools made it difficult to continue group-supported progress.

6) Finding sufficient time: One of the most commonly cited constraints was the ability of all team members to meet on a regular basis for sufficient periods of time.

This program was meant to be adopted by groups of teachers who volunteered to participate in this pilot effort. Many of the teachers in our focal schools were not volunteers. This was a departure from the design intended by program developers. Activities that teachers were required to do as part of this program - for example sharing gaps in knowledge with peers and leaders from outside of the school—were not familiar practices for many teachers and were difficult within the team given the dynamics described above.

\section{Impact of Program}

Given the research design and implementation challenges described, measurable impacts from this study were limited. By the mid-point in the school year, six of the 40 teachers interviewed reported some success from the various strategies described in the program materials that they had used. Among teachers, the most popular aspect of the intervention was the use of "studentfriendly language" in describing learning targets and designing ongoing classroom assessment. Toward the end of the school year, qualitative data suggested that more teachers had begun to use and have some success with assessment for learning strategies as described in the program materials. However, survey data did not support a similar conclusion. The survey did not demonstrate a change in assessment knowledge or confidence among teachers on the learning teams. Neither were there reports of dramatic changes visible in survey data about teacher assessment practice. Those changes that were visible suggest that teachers were engaging in certain less desirable practices (e.g., grading practice work, conflating effort and achievement) less frequently. In combination with interview data from teachers, it is possible to see teachers feeling more confident in certain practices encouraged by the program including using assessment to build students' desire to learn, communicating goals to students, and involving students in goal setting. 


\section{Conclusions and Recommendations}

The findings and impacts from this study raise several important points for those seeking to implement and support a similar school improvement program.

\section{Lessons for States}

Cross-site meetings allowed teams to hear what others were doing to support their schools. This information sharing was essential for ongoing improvement and recommends the use of pilot programs and formalized ongoing evaluation as a means of addressing implementation challenges. State teams were able to address implementation challenges by building expertise (human capital), building relationships among state team members and with other resources (social capital), and shifting some responsibilities to make time available for direct interaction with the schools (physical capital). Without this infusion and reconfiguration of capital, support for the schools would not have been possible. The most commonly cited success of this project was a newfound recognition of the volume of resources and support needed for successful professional development.

\section{Lessons for Schools and School Leaders}

Those teams that experienced direct involvement of a school leader were more focused in their work. In most schools in this project, formal school leadership (principal or assistant principals) were not involved in the work of teacher teams, beyond brief and intermittent conversations. In those schools where school leaders participated actively by joining a team or discussing in-depth ways of incorporating team learning into the work of school leadership, teams made more progress.

\section{Lessons for Teachers and Teams}

While many teams initially focused on the new content of the program, it became clear that the process of engaging with material was as challenging as the content for teacher learning teams. The process of building teams in which teachers felt secure to discuss their practice and gaps in their knowledge was a challenge for many teachers. Teachers also required assistance with both pedagogical and content knowledge. This program began to help teachers identify the knowledge that students possessed as well as gaps in that knowledge. It did not necessarily help teachers with content-based strategies for addressing those gaps. Finding the right composition of learning teams, broad instructional strategies, and content area expertise must be taken into consideration. Finally, teacher investment in this effort at the individual and team levels requires that project leaders (1) identify where this effort fits among all of the other professional commitments that teachers are asked to make and (2) demonstrate how the new material will enhance or build upon the knowledge and skills that teachers bring to their work.

\section{Concluding Thoughts}

In several cases, teacher learning teams made strides that were in line with the program expectations. However, such significant growth was the exception rather than the rule. Where it occurred, strong progress resulted from individual teachers or state leaders assuming strong leadership roles within teacher teams. This study speaks to the need for committed leadersboth philosophically and in terms of resources - to plan carefully and devote energy to move a new project forward. This project also attempted to move away from isolated professional development efforts by providing ongoing collegial support to teachers in addition to introducing the principles of assessment for learning. Such ongoing and team-based support posed a host of challenges of its own. Recognition of and pro-active planning about the issues raised in this report would provide the potential for smoother implementation and greater impact. 


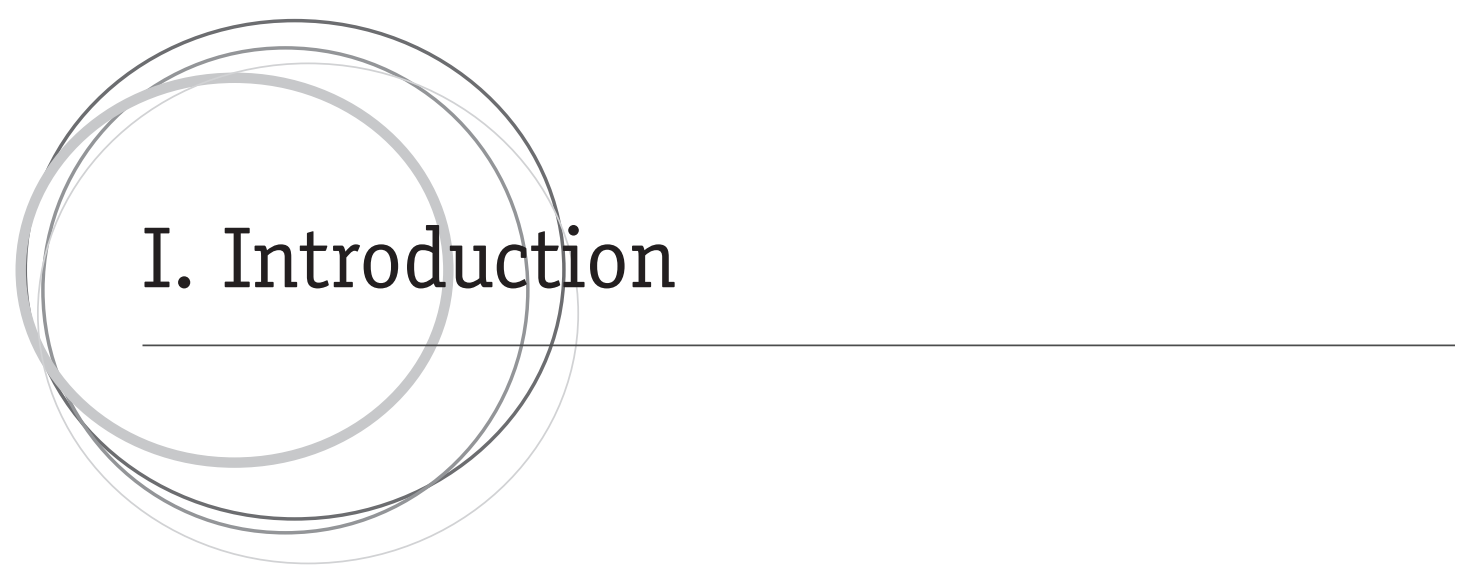

In the fall of 2006, the State of Delaware and the Council of Chief State School Officers (CCSSO) partnered with the Consortium for Policy Research in Education (CPRE) to conduct an evaluation of a ten-state initiative to enhance assessment practices at the high school level. This improvement effort, funded by a grant from the United States Department of Education, was conceived to help states with "the development of innovative products or procedures to improve the quality, validity and reliability of State assessment systems" (U.S. Department of Education, 2008). The ten states participating in this effort committed to using this opportunity to review their assessment programs and to focus on classroom-based assessment in particular. By building state and school familiarity with instruction that uses assessment to help the learning process, the states posited that teachers would be more effective in their practice and students better able to meet standards.

The CPRE evaluation of the ten-state improvement effort had three primary goals: (1) to document the experiences of state, district, and school leaders in learning about classroom-based assessment; (2) to formatively evaluate the program to promote on-going improvement during the grant period and beyond; and (3) to provide a summative evaluation of the intervention to understand its implementation and impacts on state, district, and school practice. The first two of these goals were ongoing endeavors over the course of the grant and were accomplished through the scheduling of regular meetings with project leadership and the sharing of findings with leaders from all ten states. This report seeks to fulfill the third goal with an analysis of the implementation of the initiative, a discussion of the lessons learned, and a review of the impacts that could be documented.

This report will begin with a description of the project as it was designed by the State of Delaware and CCSSO. Following the project description, there is a discussion of the guiding research questions, evaluation design, and data analysis. The bulk of the report is devoted to a discussion of findings related to implementation and impact, as well as the implications and lessons for future undertakings.

\section{Project Description}

The grant that funded this effort was known as an Enhanced Assessment Grant (EAG) and was developed by the U.S. Department of Education in order to:

"(1) improve the quality, validity, and reliability of state academic assessments; (2) measure student academic achievement using multiple measures of student academic achievement from multiple sources; (3) chart student progress over time; and (4) evaluate student academic achievement through the development of comprehensive academic assessment instruments, such as performance and technology-based academic assessments" (U.S. Department of Education, 2008). 
Delaware education leaders and CCSSO pursued this opportunity with the understanding that many states already had spent significant time and resources focusing on summative statewide accountability assessments and wanted to consider a broader approach to assessment. Integral to their thinking was the idea that in addition to its evaluative function, assessment could be an ongoing process, integrated into instruction, that could help teachers better meet the needs of students in advance of their annual statewide assessments. Rather than attempt to develop or improve a new product, leaders of this project chose to use resources to help teachers and school leaders develop capacity to use assessment effectively in their own classrooms.

According to its initial design, the Enhanced Assessment Grant being evaluated in this report had four goals. Below, each goal is stated and followed by a brief summary of the project designers' intent.

Goal 1: Develop and implement a practitioner- and research-based vision of a comprehensive and balanced assessment system.

This effort was designed in part to encourage state teams to think about assessment beyond the traditional focus on summative assessments. Project leaders hoped to push state participants to define a vision for, and systemic framework to support, a balanced assessment program that would include both the formative and summative uses of assessment as well as the instructional and motivational purposes that assessment can serve. The systemic approach included a desire for states to consider the implications that a broad approach to assessment would have for teacher preparation, policy, and accountability.

Goal 2: Build state leadership capacity and support each state's technical assistance to districts and high schools in providing high-quality professional and leadership development in balanced assessment systems and specific practices of assessment for learning.

The project leaders sought to develop state leaders who would be "able to communicate the importance of the classroom level of assessment" and its place in the broader assessment system. This goal would be met by providing professional development that would expose state leaders to the knowledge and materials necessary both to understand more about assessment and to help classroom teachers improve their ongoing assessment practices.

Goal 3: District/high school teams begin to implement a vision of assessment for learning in schools and classrooms.

The bulk of program resources and attention were devoted to achieving this goal. Each state-level team was to establish partnerships with two to four high schools in their states to implement strategies associated with assessment for learning. In essence, each school involved in the project would set one or two voluntary teacher learning teams which would use a designated set of materials to familiarize themselves with this approach. Because this goal consumed the majority of program resources and attention, it is the focus of this report. 
Goal 4: Generate and disseminate tools, techniques, and new knowledge to support future approaches to teaching and learning, while strengthening the commitment to all students learning at higher levels.

This goal speaks to the collaborative nature of this project. Throughout the process, all participants were expected to share with the multi-state group their experiences and tools they developed in support of the first three goals. In addition, participating states and schools agreed to disseminate information about their project as well as the research instrumentation that was developed among participants and through other venues (e.g., publications, conferences, etc.).

To meet the four goals identified above, CCSSO solicited ten states to volunteer to participate: Arizona, Connecticut, Delaware, Iowa, Louisiana, Maine, Michigan, Nebraska, North Carolina, and Virginia. Each state was required to establish a leadership team to guide and support this effort, although the staff composition of the teams varied significantly across the states. Team sized ranged from six to ten people. Members often included directors of assessment, high school directors, directors for English language learner or special education programs, or other curriculum support staff. States' participation was contingent on the understanding that they would recruit two to four high schools to partner with them on this pilot project.

Figure 1. Participating states.

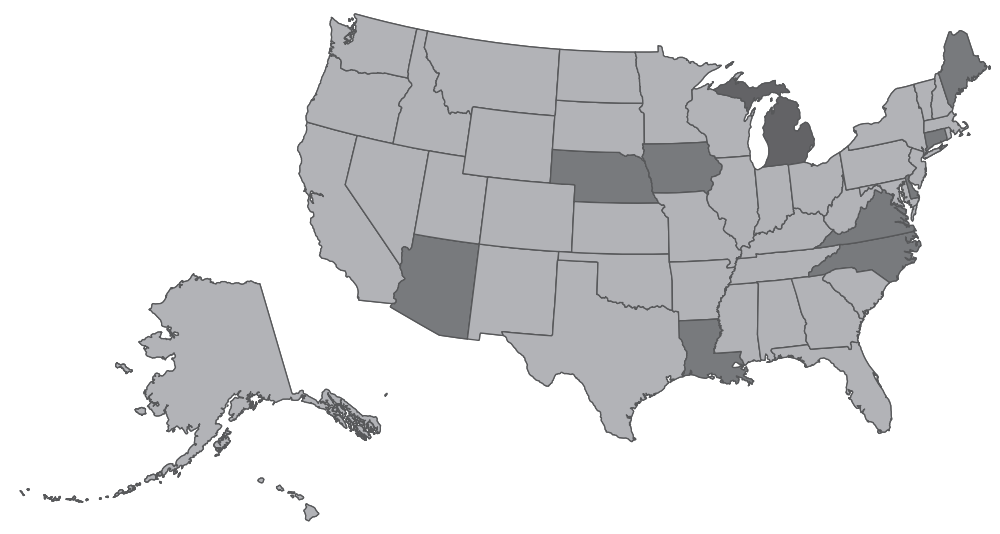

The newly formed state-level teams were introduced to the program, its structure, and materials via an interactive Web session. Then, in December 2006, most of the state teams came together for an in-depth introduction to the program materials (those who could not attend that introduction attended a similar program the next month). This two-day orientation focused on giving the state teams tools they could use to introduce the core concepts and processes of the materials to potential partners, not on making state teams into experts or trainers.

The introductory session for state teams introduced the main ideas of the new approach to assessment. In addition to discussion of the ideas and themes supporting this approach, state teams were provided with the resources to plan and create introductory presentations to use in introducing the learning team strategy to potential partnership schools. Given its brevity, this session offered an overview of the content and process that schools were meant to use to modify classroom practice. 
State teams were then expected to introduce the concepts supporting improved classroom assessment (and the specific materials) to schools and to support school teams in their learning. Teams of teachers at the school level were expected to learn from the supplied materials, try new practices in their classrooms, and reflect on and change their practice. The program was designed for school-level teams to be supported, but not run, by the state.

Following this orientation, states were asked to identify and recruit high schools to work in a partnership to achieve the goals stated above. Based on priorities described in the initial grant application, states were told to recruit "high-poverty, low-performing high schools." States interpreted these guidelines differently, but generally recruited high schools that had been identified as not making "adequate yearly progress" under the definition of the No Child Left Behind legislation. Below, the school recruitment process and challenges are described in more detail. In total, 30 high schools participated in this project across the ten states.

\section{Project Materials and Supports}

The primary materials that were introduced at the initial orientation meeting and that school teams worked with were designed by the Assessment Training Institute, a division of the Educational Testing Service (ETS). The materials are "grounded in the research shown to increase student motivation and learning through improved classroom assessment" and are designed to help "educators increase knowledge and skill in student-involved classroom assessment" (ETS, 2008). State and teacher teams were supplied with three discrete items produced by ETS for this purpose. The first was a text and workbook, Classroom Assessment for Student Learning (CASL), designed around several keys to improved classroom assessment. It comes with suggestions for classroom practice and is designed to be used by teams of teachers. It has a CD and DVD with additional examples and materials. Each participating teacher and state team member received this text.

The CASL text has 13 chapters that seek to help teachers to form a learning team, to learn about using assessment to motivate student learning, to make clear various types of learning targets, and to design assessments that match learning targets. The text then goes into depth about four types of assessments—-selected response, extended written response, performance tasks, and personal communication as assessment—spending one chapter on each type. In the final part of the text, there is information about communicating assessment results to various audiences and for different purposes, guidelines for using assessment information to create report card grades, using portfolios effectively, holding conferences with and about students, and providing guidance about standardized assessments and their place in the assessment system.

The CASL materials are based on research about the classroom uses and impacts of formative assessment, most notably the work of Black and Wiliam (1998) and Sadler (1989). According to the text's authors, this research indicates that a successful assessment environment will ensure that students and teachers are clear about learning objectives, about students' current knowledge and skills, and about their respective roles in closing the gap between objectives and current status. To accomplish this, the authors argue, assessment for learning will include assessments well-matched to the stated learning objectives, descriptive feedback, and student involvement in the assessment process.

Shortly after the introductory session, each school and state received the Professional Development Package, which includes seven DVDs on topics including evaluating assessment quality, 
designing and evaluating performance assessments, involving students in discussions of their own progress, using assessment for student motivation, and several other topics. The Professional Development Package also includes texts for further information on the roles of school leaders, creating rubrics, and understanding assessment for parents and community. Unlike the CASL text, which teacher teams are meant to work through in its entirety, the professional development package can be used as a resource to go in depth in particular areas of interest or need.

The final element that states and school teams received —-somewhat later than the other materialswas a team facilitator handbook. This handbook provides an overview of each CASL chapter, directs the facilitator in effective ways to introduce the chapter, and provides cross-referencing to guide team members to additional information about areas of interest in the books and DVDs that have been supplied to them.

In addition to the provision of the materials described above and the availability of state teams for support and guidance, the project provided a number of other ongoing supports. Between January, 2007 and June, 2008, the project leadership arranged for six interactive Internet meetings on topics including assessment for students with special needs and the necessity of developing learning progressions, and also several sessions related to particular parts of the ETS materials described above or to project communication technologies. In addition, the developers of the ETS materials made themselves available to state teams for additional help and guidance about strategies for leading school teams. Six of the ten states took advantage of this opportunity for further guidance. CCSSO also created a Web-based discussion board for team members to raise issues and questions. Despite several efforts to stimulate conversation on the website, it was used rarely by project participants. In addition, there was a second two-day meeting for state teams held approximately six months into the project (July, 2007). This meeting was an opportunity for states to share strategies and experiences to that point. Meeting participants also were provided with several hours of additional introduction to the CASL materials. Table 1 provides an overview of the project timeline and related activities.

Table 1. Project timeline.

\begin{tabular}{ll}
\hline Date & Project-related events \\
\hline November, 2006 & Web introduction for state teams \\
December, 2006 & Two-day orientation for state teams \\
January-April, 2007 & State recruitment of partnership schools \\
March-June, 2007 & Introduction of program to schools and teams \\
May-September, 2007 & Web-based sessions for state and school teams \\
July, 2007 & Second meeting of state teams \\
June, 2007-June, 2008 & Teacher teams working in schools \\
\hline
\end{tabular}

With help from the CASL text and related materials and the host of other supports described above, teachers were expected to change their assessment practices in ways that promote student learning. This approach requires teachers to create assessments and two-way feedback systems that allow them to more effectively measure student learning and identify gaps in learning in order to effectively scaffold instruction to meet student needs. The CASL materials provide a variety of strategies to accomplish this, including varying assessment types and matching them to learning goals, involving students in the assessment process, and developing reporting strategies that allow students to better understand their strengths and weaknesses and how to address them. 


\section{Evaluation Questions and Rationale}

This evaluation focused most heavily on the implementation goal of the project, identified as Goal 3 above. The primary interest of the pilot study has been in the ability of state teams to stimulate improvement in schools using the teacher learning team model. In the context of this project, catalyzing change at the school level is viewed as being dependent on the capacity and role of state leaders as well as the capacity and role of the school teams. The focus on this particular challenge is informed by three important strands of prior research.

First, previous education research has shown that state policies are altered in a variety of ways as they move through multiple administrative levels and are interpreted to fit the local school contexts into which they enter (Cohen, 1982). Teachers and school leaders make sense of new policies and practices based on their own knowledge, ability, and experiences in ways that significantly impact the enactment of policy as intended by its creators (Spillane, Reiser, \& Reimer, 2002). Given this research base, we seek to assess the extent to which the goals and vision of classroom-based assessment are productively adapted at the local level (McLaughlin, 1976) in ways that meet the needs of both state-level policy makers as well as the "street-level" actors (Lipsky, 1980) at the district and school levels.

Second, research suggests that enactment of the range of complementary assessment practices is relatively rare in schools (Supovitz \& Klein, 2003), even while use of formative and benchmark assessments has been shown to be powerfully associated with gains in student learning (Black \& Wiliam, 1998; Crooks, 1988). Traditional understandings of the use of assessment dominate teacher practice, while using assessment as a motivational and instructional tool is a relatively new concept for most teachers (Butler, 1988; Dweck, 2001).

Third, recent school-improvement efforts have put a great deal of faith in the concepts of professional communities or teacher learning teams. There has been significant research and writing about the benefits of such teams in stimulating teacher learning and reflection (DuFour \& Eaker, 1998; Marzano, 2003). Research in this area has focused largely on the process and function of these learning teams (Little, 2002; Thomas, Wineburg, Grossman, Myhre \& Woolworth, 1998; Wineburg \& Grossman, 1998). It has shown that teacher learning communities, teacher teams, and increased teacher communication can be used as a primary means for school improvement and teacher learning (Crow \& Pounder, 2000; Pounder, 1999; Quinn \& Restine, 1996). The project that was evaluated (and described above) depended heavily upon teams for exploration and utilization of the knowledge and information provided to the teachers. This project and this evaluation report make a contribution by spending considerable time studying the systemic conditions that lead to more or less successful functioning of such teacher teams.

Thus, the evaluation focused on three primary research questions: (1) How does the knowledge and skills that are built among and disseminated by state-level leaders get mediated and implemented at the state, district, and school levels? (2) What are the facilitators of and obstacles to implementation and operation of learning teams at the school level? (3) How, if at all, are school and teacher knowledge and practices influenced in ways that allow for meaningful use of balanced classroom assessment practices? 


\section{Data}

This report relies on several sources of data: observation of trainings and meeting, interviews with state leadership in all ten of the participating states, interviews with teachers and school leaders in five high schools in two focal states, and surveys of teaching staff in those same schools. Data in this report from state leadership come from all ten of the participating states. Individual and group interviews were conducted twice with state leadership teams from eight states and were conducted at least once from all ten states. Interviews with state leaders focused on the introduction of the program to high school partners and the supporting roles that state teams played in the implementation of this program.

All of the data from teachers and school leaders included in this report is from high schools in the two focal states. Structured interviews were conducted with all participating teachers and administrators at the focal high schools. Seventy interviews were conducted with 43 teachers and leaders at the five focal high schools. Interviews were conducted in the spring and fall of 2007 and again in the spring of 2008. In total, 100 interviews were conducted with 65 individuals. In addition, CPRE research staff observed the two state-team training sessions as well as trainings for school staff in both states.

The evaluation of this project began with the documentation of professional development and technical assistance opportunities. In order to accomplish this documentation goal, the primary researcher observed the initial orientation and training events for state leadership teams.

Researchers then interviewed participating state leaders about their training and the development of state plans for achieving their goals. State action plans were collected and subjected to document analysis.

In order to evaluate the change process in sufficient depth, this evaluation focused closely on two states while gathering data with less intensity from the other eight participating states. These two states were selected with two criteria in mind: They would be sufficiently close in proximity to one another to allow for regular in-person visits by the researchers, and they would represent the range of strategies being pursued by all ten participating states. In the two focal states, the study focused on two state/district/high school partnerships. This nested evaluation design matched well with the project goals, which sought to provide state teams with the knowledge and skills to create an effective balanced assessment system tailored to the particular needs and contexts of districts and high schools.

Through both on-site observation and interviews with state- and school-level participants in the learning teams, the work of the teams was documented as they pursued the goals identified in their state action plans. In order to gather qualitative data about the progress of teacher learning teams and the impact that the intervention was having at the school level, two researchers interviewed teachers in a sample of five high schools across the two states. Interviews focused on the dynamics and function of teacher learning teams and how practices related to classroom assessment may be changing as a result of teacher participation in the project. The initial evaluation design included a plan to interview central office-level participants. However, it became clear that in the states chosen as the focus of this study, central office staff-member involvement was peripheral to the project following their initial agreement to allow schools to participate. 
As part of the ongoing effort to document the project activities, researchers observed the second training meeting for state teams. Because this was an opportunity for state teams to clarify their visions for balanced assessment and enhance their strategies for providing support and technical assistance to district leaders and high school teams, it was important to understand the midcourse corrections that were developed during this second training opportunity. Following the second training, state teams were expected to continue their work with district and school leaders. In order to capture the effects of this additional training opportunity for state leaders, researchers again interviewed school staff members in the two focal states. This second round of qualitative data collection at the school level provided evidence of the continuing evolution of learning teams, changes taking place in teacher practice, and any value added by the second professional-development opportunity for state teams. In addition, it provided a second opportunity to talk with teachers about the use of project materials.

Our evaluation also included quantitative indicators to assess the impact of this project on teachers' assessment practices. Based on the training that state leaders received, on our analysis of states' action plans, and on instrumentation already developed by Assessment Training Institute, CPRE developed a survey instrument to assess teacher knowledge of, and comfort with, classroom-based assessment practices. (The survey can be found in the Appendix.) The survey was administered to all teachers in the five focal schools. The survey was administered at two time points: first, just as the program was introduced to schools (May/June, 2007), and second, one year later after teacher teams had been working together for much of the school year (May/June, 2008). This pre- and post-test design provided quantitative data about changes in teachers' understanding and practice attributable to the intervention. The teacher survey was administered in all five focal schools. In round one, 330 completed surveys were received, and 299 were received in round two for an overall response rate of $76 \%$. Because the initial conception of this project assumed that the new assessment ideas might spread to other teachers in the school, we chose to survey all teachers in the five focal high schools. However, given the way in which the program was used in those schools and a review of the survey data from all teachers in the schools, it became clear that there was no impact on non-participating teachers. As a result, findings in this report about the impact of this project relate only to surveys from those teachers directly involved in the project who were team participants at both times that the survey was administered—a total of 26 teachers across the five schools. 


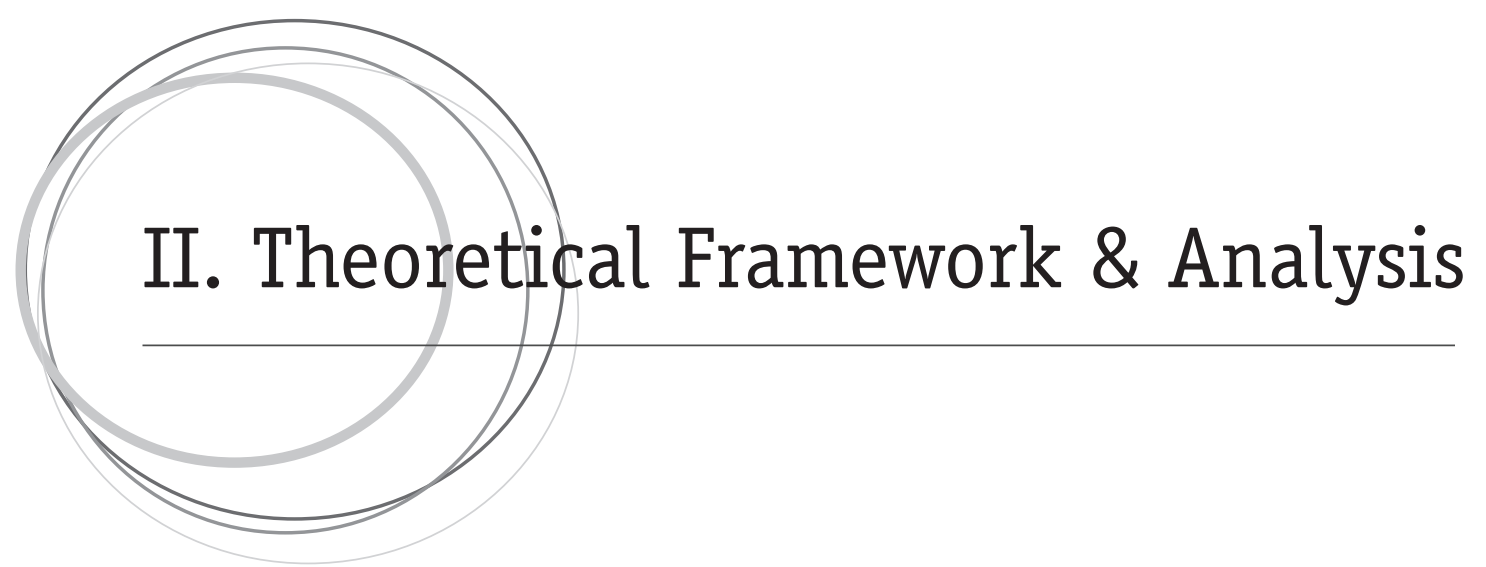

In order to look at the implementation and impact of this project on multiple levels of the educational system, this evaluation uses a structuralist perspective. Here, structuralism follows the work of Levi-Strauss (1963) and examines the roles and relationships of the primary actors in this process. This framework provides a stable set of categories with which to analyze a large quantity of qualitative data. Because the goals and design of the project being evaluated closely followed the traditional organization of educational governance and policymaking, this framework seems particularly appropriate for this evaluation report. While not insensitive to the critiques of thinkers like Barthes, Foucault, or Derrida, poststructuralist positions such as theirs would make the descriptive and evaluative functions of this report difficult for the reader. Instead, this report takes a more traditional approach while being sensitive to the valid perceptions, accounts, and interpretations of actors at all levels of the system. Though respondents are identified by their position within the larger system (state, district, or school staffs), each individual is considered equally capable of providing her or his perspective on the implementation and impact of the program being evaluated.

As is evident from the project description, ETS shared information with state team leaders. This information came in the form of in-person presentations, Internet-based presentations, and prepared materials including printed training documents, published texts, and audio-visual aids. These leaders were then expected to introduce the information and the ideas that undergird it to teachers. In most cases, this plan also required that states share the information with central office and/or school leadership. The project did not specify a role for these actors at the outset. As a result, the relationship of central office and school leadership to the teacher teams was of an indeterminate nature at the outset (as illustrated by the dashed line in Figure 2) and varied as the project proceeded. Following this framework, analysis and findings focus on the roles that various actors have played in the program—leaders at the state, district, and school levels, and the teachers, in that order.

Figure 2. Structuralist framework.

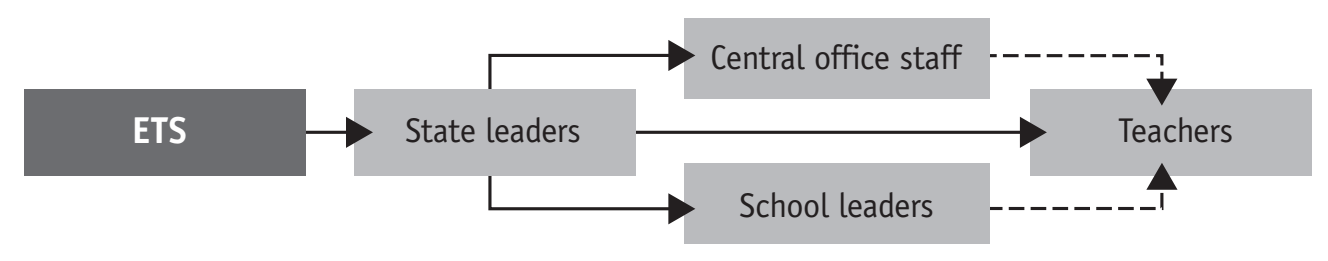




\section{Analysis}

The overall strategy for this analysis was to use mixed methods to assess the extent to which the project has been successful in creating the conditions needed for the effective use of balanced classroom assessment programs. In the analysis process, we sought evidence that connects the observations, interviews, and survey data in an effort to identify (1) the portions of the project that brought schools closest to state goals and (2) those parts of the project that appear to have less or no effect or even served as obstacles. We have paid special attention to the ongoing nature of relationship between the state teams and the project supports that are described above, and the relationship between state teams and their partnership high schools.

In addition to the careful documentation of project activities, we analyzed the qualitative data in order to chart the progress of the project as it is defined in the initial orientations and state trainings, as it is interpreted and presented during the state/school team meetings, and as it is implemented at the school level. By gathering data at the state and school levels, we gained insight into each step of the process and analyzed it multiple times. Extensive notes were taken during interviewing and each interview was digitally recorded. Notes were read and coded for emerging themes after each round of interviews and direct quotes, where relevant, were taken from interview recordings. Themes were drawn from the evaluation questions and theoretical perspective discussed above and included concepts related to individuals' roles, supports, obstacles, assessment experience, changes in thinking, and changes in practice. In total, the qualitative data provided information about shifts that occurred in participants' understanding of the essential elements of classroom assessment at the school and state levels and the reasons for those shifts.

Our quantitative data provided information about the status of self-reported teacher knowledge and practice related to a variety of assessment practices, as well as their sources of information about classroom-based assessment. The first round of survey data provided helpful contextual information to guide our early qualitative inquiries and, in combination with the second round provided a context in which to place our qualitative findings. The second round of survey data allowed us to examine changes in teacher knowledge and practice among participating teachers that can be correlated with the goals and materials of the ten-state initiative. 


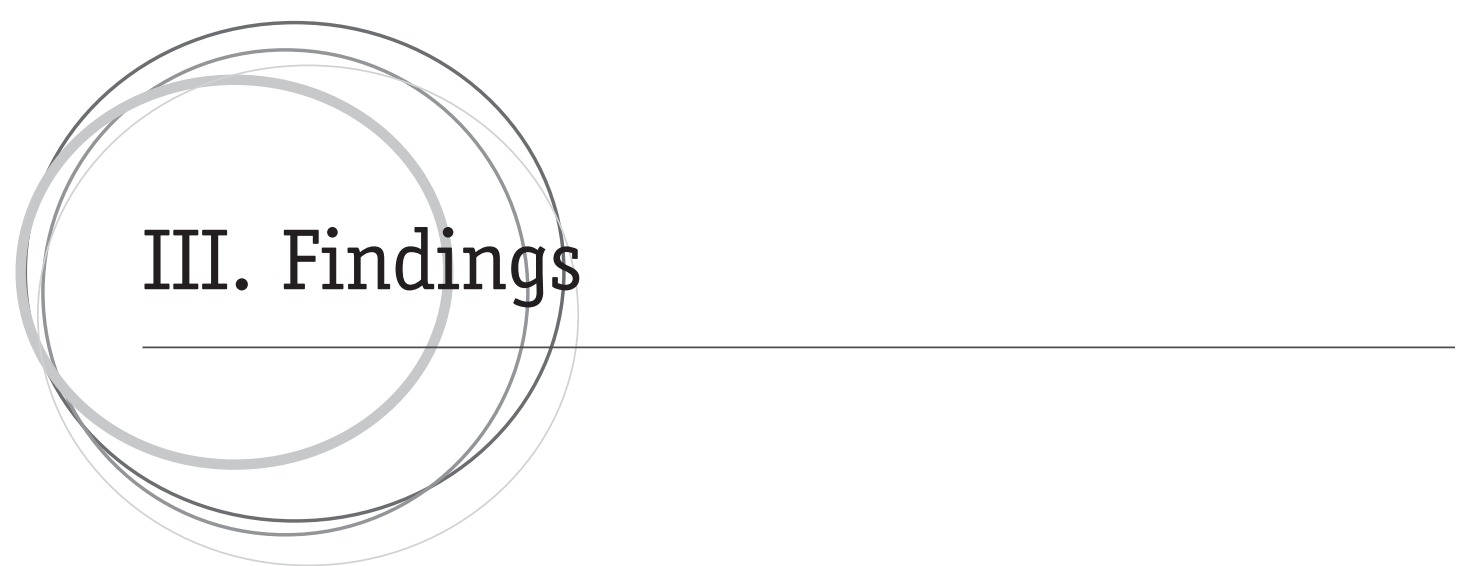

As stated above, this evaluation focuses most heavily on the elements of this project that have direct bearing on the process of establishing learning teams at the high school level and subsequent changes in teacher knowledge and practice. However, I will briefly address the other goals before providing a detailed discussion of the learning teams' implementation and impacts.

In pursuit of Goal 1-to develop a vision of comprehensive and balanced assessment-all of the states that participated in this project spent significant time working on articulating and supporting a vision of assessment that includes formative and summative elements. While many of these efforts were underway in parallel with the unrolling of this project, state participants said this project helped to further their thinking in this area. Examples of progress in a vision for assessment that were coincident with this project included North Carolina and Maine, each of which generated documents articulating a broad vision of assessment for the state. Other states, including Arizona and Connecticut, devoted staff time to promoting formative and classroom assessments and generated materials that schools and districts can use to further their work in this area. Iowa and Nebraska—states that had embarked on supported a balanced assessment approach prior to their participation in this project-continued to enhance and develop their support of particular schools and districts as exemplars of good performance as part of their involvement in this effort.

Goal 2 of this project- to build state capacity to support the development of balanced assessment systems - was pursued through the state orientations, trainings, and supports described above. State leaders reported being inspired by introduction to the ETS materials and also reported that individual communications with material producers that occurred during the course of the project were particularly helpful in strengthening the guidance that state teams were able to give to their partner schools. As one state leader said, "The support that we got from [ETS], the conference call that we had with Rick Stiggins a few weeks ago was great, fabulous. I didn't feel like we were out there all by ourselves." There was very little discussion of the role this project may have played in supporting any larger development of statewide systems. To most participants, that goal seemed beyond the scope of this project and the supports that it offered.

Goal 4-dissemination of new knowledge and information generated from this project-was pursued within the project through periodic sharing by states of their lessons and experiences, through the development and sharing of research instruments to study this project, and through the presentation and writing of reports such as this one.

The vast majority of time and resources of project participants was devoted to Goal 3-implementing assessment for learning at the high school level. Analysis of progress toward that goal consumes the remainder of this report. Stated briefly, over the course of the first full school year in which teachers were expected to be working with the project materials, we found that in the five focal high schools: (1) learning teams struggled to meet on a regular basis; (2) program materials and resources were used in limited ways; (3) discussion or evidence of any change in 
classroom practice did not come until the spring; and (4) school teams frequently remained somewhat unclear about the intended "outcome." As described under the framework, I will discuss the roles each of the primary actors played in the progress of this project.

\section{State}

At the start of the project and during the process, states had varying ideas about the role that their state teams would or should play. State plans ranged on a continuum from a high level of involvement to a lower level of involvement in the ongoing work of the schools (Figure 3). Given the varying nature of state departments of education, states were encouraged to design a strategy for introduction and support that they felt would best work in their contexts and that would meet school needs.

Figure 3. Continuum of state involvement.

Participation on school learning teams

Initial training
and participation,
planned to
taper off

Initial training planned to taper off

Initially, two states envisioned a higher level of involvement for state team members, with a member or a couple of members of the team participating on school learning teams to work through the material together with the teachers. As one state leader described it, the intention was to "have somebody there with the team, as part of the team or advising the team" (SL1-1)1.

Two other states planned to participate actively in initial training for teachers around both content and process and then to let the teams work more independently. These state teams saw their roles as becoming familiar with the work and the teams and then serving as a resource when needed. As one described it, "We would like them to be self-motivated and to move forward knowing that they have these little safety nets behind them, whether it's to check in periodically or...that they feel free to call us. For us to move them along didn't seem like a model that was very sustainable" (SL3-2).

Most of the states (four of ten) planned a system of periodic check-ins by state team members who would guide and connect the school team to resources as needed. At the low-involvement end of the spectrum, two state teams felt that they wanted districts, schools, and teachers to take ownership of the process. They planned to provide schools with a primary contact person

${ }^{1}$ Identities of all respondents have been concealed. Parenthetical references are provided to the reader to identify the individual, his/her position, and the time point at which s/he was interviewed. Codes are as follows: SL refers to a state leadership team member, TT refers to a member of the teacher learning team, and PP refers to a principal or assistant principal primarily involved with this effort. The number that follows those two letters is an individual identifier so that the reader has a sense of the variety of voices being heard. The number after the hyphen provides a general idea about whether the data came from the first or second round of interviews (loosely, the autumn of 2007 for round 1 and the winter or spring of 2008 for round 2). 
and any support that was requested, but they generally planned a largely "hands-off" approach to the working of the teams. As one state team member described the thinking, following the initial introduction to the materials, it was the intention to "drop this box in the school and see what happens" (SL2-2). In many cases, state teams articulated a vision of their plans, but recognized that their approach to working with school teams would have to be negotiated with school leaders and the teams early in the process.

Between September, 2007 and March, 2008, the six states that began their work in the lower half of the spectrum began to migrate toward the higher end of the spectrum. This migration occurred beginning with the very early stages of the program as states confronted a number of unanticipated challenges including difficulties with recruitment, becoming acquainted with the material, and negotiating a new type of state-school relationship.

The first challenge that many states faced was in recruiting schools. Because participation was voluntary on the part of schools, many schools declined the offer to participate. As stated above, the grant asked states to target low-performing schools. In most states, that meant that the teams approached schools that had been identified as needing improvement based on state test scores. Feeling overwhelmed with other improvement efforts, many school leaders did not feel they had sufficient teacher time to create space for this effort. As one state leader explained, "There is some concern about how they can do this in addition to all of the other things that they're taking on." As a result, many states went through several rounds of negotiations with schools that ultimately declined to participate. That same state leader echoed the approach of others when she said, "We know that as a state team we really have to keep on top of that to reinforce how this can just be so infused with what you should do day to day" (SL4-1).

States found that they had to become increasingly assertive in encouraging schools to take part. States tried hard to make explicit how this project related to other projects that might be under way. "Every school is doing projects and we have to focus on the merging of those projects into a whole" (SL5-1), one state leader said. In some cases, states hoped to leverage previous connections with high schools to convince them to support multiple projects. For example, one state leader explained, "We think this project will work because they are intensely involved with us with the College Board around the [Advanced Placement] project and the teachers there are getting a lot of pedagogical content knowledge around AP" (SL6-1).

Even in places where school leaders agreed to make this program available to teachers, it was frequently difficult to recruit teachers to volunteer. The materials used in this program are quite explicit in stating that teachers should be participating in the learning teams voluntarily. Experience has shown that the teams are most effective when participants choose to be a part of the team as opposed to being required to be there. In this project, the willingness of teachers to participate frequently depended on the incentives that states or districts could offer to teachers. As this became clear to state leaders, most states made arrangements to offer professional-development credits or additional pay for the time that teachers were investing in the program. States arranged for graduate-course credit, state-recognized professional development credit, or overtime pay. Alternatively, state leaders suggested to schools or districts that this project be required of teacher teams that were previously established. State and/or school leaders frequently overlooked the suggestion that this be undertaken by volunteers. As one state leader said about her partnership schools, "It isn't voluntary in any one of them" (SL7-1). 
States also had to work hard to find common meeting times for their team members. Team time was needed both to deepen members' knowledge of the material and to meet with school-level actors with whatever frequency the state envisioned. For the most part, state team members did not have any deep knowledge of the program materials at the start. As a result, even to offer the most minimal levels of support, state teams felt the need to become familiar with the considerable material that had been provided to the schools. In addition, state teams created a sort of "sales pitch" to entice school and district leaders to take part in this project. Both of these activities required considerable time from state team members. Because this was a relatively short-term (18-month) pilot program, it was tacked on to the jobs of people who already had fulltime jobs in the state departments of education. Carving out sufficient time to tend to the program was a challenge that many states had not fully considered at the outset.

Finally, as the state teams worked with school teams, they had to negotiate a host of issues. As one state leader said, "We're not in the habit of providing ongoing professional development. We create nice documents to share and introduce those, but we don't usually do long-term stuff" (SL3-1). This program introduced a new model of professional development in many states. For the majority of states that planned a less-involved role, the challenge of how to stimulate and start the teams, do some monitoring of their work, but not be seen as the necessary element in moving the work forward, was a difficult balance to strike.

Increasingly, states saw themselves as the essential element in moving the teams forward in their work. "They don't really need us a lot, but they like us there" (SL3-2), one state leader said. Other states reported significant differences in the progress and success of those teams where a state team member was a regular presence in contrast to those that tried to work in a more independent fashion. As one state leader said, looking back on the experience of her team: "I think we proved beyond a shadow of a doubt that there is the need to have somebody maintain really close contact with [the school], provide some leadership. The materials are not stand-alone materials. I've emailed and I don't always get a response. I live in the town so I've stopped in a couple of times and talked to the principal. I didn't want to impose myself when I first started out. We were trying to do a sort of hands-off but I told them I would come any time they need me. If they hit a snag, they could contact me. And there has been little contact other than my initiating it or stopping in and saying how is it going and that kind of thing" (SL8-2).

Where states were a bit more proactive and present in the schools, teams did form, but were dependent on the state for continued momentum. As one state leader who was a regular presence in one school said, "It was supposed to be a kind of a self-maintaining thing, although we had envisioned it being self-maintaining because of the momentum of the learning teams, and it's kind of become something that the DOE has pushed the momentum" (SL9-2).

Other state leaders reported much more regular contact with school teams, with state staff attending every teacher learning team meeting. The transition to more active and regular participation was a process that occurred over time in most states. As one state leader said when describing the lessons learned through more involvement with teacher teams, "We learned the most effective way to implement this was by having to be involved. We've learned a lot about working with the schools and working with teams of teachers. They don't want the autonomy. They want the leadership and the direction from the state. In order to get them involved, we had to provide that...we would have started this completely differently and would have saved a lot of time" (SL10-2). While they are pleased to be able to do this work with a small number of schools, they realize that this type of relationship cannot be scaled up given current state department capacity. And, for most of the states, it was not the type of relationship that had been initially envisioned. 
The discussion of state roles thus far has focused on the impressions and comments of state leaders. However, because the focus is on the implementation at the school level, we now turn to a discussion of how teachers experienced this new relationship with the states. These data are drawn from the two focal states and cannot necessarily be generalized. However, these findings were shared with state leaders in six of the eight other states and generally were perceived as viable in their states.

Teachers generally felt that the introductory meetings held by state leaders were quite vague and did not provide them with sufficient detail about what was expected of them. Though they were attracted by the general concepts of improving assessment skills and using assessment to motivate students, they did not have a clear idea about how the program would be implemented or who would be running it. In part, this was due to the fact that state teams wanted to negotiate this role with schools and were likely a bit unclear themselves about how implementation would happen. However, this uncertainty appeared to make teachers uncomfortable about their roles and suspicious about the ability of the state to support this effort. As one teacher said a couple of months after the teacher teams had been expected to start their work together, "We haven't gotten a real clear-cut idea of how we are supposed to move forward. We're not given 'you need to hold meetings on this, you need to be doing this part of the assessment when you're doing this.' I think it was kind of given to us in a packet and a book, but not really explained. As teachers - most of us - if you took two hours and said I want to go through what the requirements are...that would help, for us to know what we were getting into, what we were involved in, how we needed to structure our lives to do it. We just weren't aware what we were supposed to do" (TT1-1).

Teachers also expressed a lack of clarity about the mission or goals of the grant project. One teacher summed up the question of many when he said, "How do we comply with the requirements of this grant?" (TT2-2). Though state teams were generally clear that the goal was to enhance classroom assessment practices, many teachers were accustomed to a more compliance-oriented mentality and wanted to know what deliverables or products were expected of them. Without these sorts of guidelines, teachers felt a bit adrift in the sea of materials they had been given. Several months after her teacher team had begun periodic meetings, a teacher at a different school expressed confusion about larger project goals when she said, "I guess I'm not really sure what the goals are. I guess I would think that it's focused on assessment and providing various types of assessment to the kids for all different types of learners and to give them feedback, different kinds of feedback.... and I think we have moved toward that. But I'm not sure of the other goals of the program yet..." (TT3-2). A teacher in a different state echoed these same concerns: "I feel like it's a worthwhile endeavor, but I feel like we need a better support system, a better checkpoint system, a better idea of what we hope our goal is, or our outcome is going to be from it" (TT4-2).

Teachers also wanted to feel that they had experts to turn to when they had questions about the materials. They compared this program with other professional development efforts they had experienced where experts came to the school either one time or repeatedly and delivered information. As one Assistant Principal said, "I can go in there and say, you're doing a really great job, and they are. But I didn't write the book so it would be nice if somebody from this outfit, or a representative, came down and watched a couple of classes and said you know you're doing this really well, you're doing this not so well, try this. When we did [another program] they not only presented the strategies, but they came in and critiqued us and said, this strategy went well, why didn't you try this? And it was a longer process, but in the end people felt more and more comfortable doing it in their classes" (SL6-2). 
The design of this program did not depend on the regular presence of outside experts. Teachers were expected to wrestle with the material and use it to learn for themselves. For many teachers, this was a challenge. In addition, state teams' limited familiarity with the material, particularly in the early days of the program, did not instill a great deal of confidence in teachers. As one state leader explained, "Having an expert in the room, at least periodically, when they meet might be something that would help, whether it's an expert from one of the schools in [state] or wherever they're from....would probably be more potent" (SL8-2).

Teachers also felt that they were getting mixed messages from the state. This program encourages teachers to assess students using a variety of methods suited to a variety of learning goals and to address the needs that are identified through this ongoing formative assessment. For teachers for whom this is a new concept, it appeared to conflict with the rapid progress that is required to meet state standards. This was particularly true for teachers who teach classes in which there is a state exam at the end of the year. These teachers have a very clear idea about how much time they can spend on any given topic, and their schedules often are linked directly to the test composition. As a result, teachers expressed feeling conflicted about trying to implement the practices encouraged by these new materials while pursuing the practices they felt were necessary to demonstrate success on the state exam.

Finally, many teachers reported that they did not get a great deal of recognition or support from states. In those schools where teachers were taking considerable time to wrestle with the new materials, they did not feel that their efforts were being sufficiently validated. At least initially, it was not clear that states really saw validation of teacher effort as their role. When asked about how they planned to recognize teacher effort in this pilot program, many state leaders spoke about efforts to provide teachers with additional resources for their work such as websites or trainings. However, one state leader spoke for many when he responded that they had "not consciously" thought of ways to recognize and honor the extra teacher work (SL11-2).

However, teachers in the focal states expressed the view that they wanted some notice to be taken of the effort they were putting forth to learn about these new practices. States were more accustomed to local districts or schools, not the state, delivering this sort of positive reinforcement. This issue leads us into a discussion of district and school roles.

\section{Central Office}

Just as state leaders envisioned a range of roles for themselves, at the outset states also envisioned the participating central offices playing a range of roles in this effort. The potential roles for central offices can be arrayed on a continuum similar to that of the state roles (Figure 4).

Figure 4. Continuum of central office involvement.

\begin{tabular}{|c|c|c|c|c|}
\hline \multicolumn{2}{|c|}{ High Involvement } & & \multicolumn{2}{|c|}{ Lower Involvement } \\
\hline $\begin{array}{l}\text { Central office } \\
\text { should play a } \\
\text { lead role }\end{array}$ & $\begin{array}{l}\text { Central office } \\
\text { collaboration } \\
\text { is critical }\end{array}$ & $\begin{array}{l}\text { Dependent on } \\
\text { the nature } \\
\text { of the district }\end{array}$ & $\begin{array}{l}\text { Central office } \\
\text { support (release } \\
\text { time, flexibility) } \\
\text { but no active } \\
\text { participation } \\
\text { needed }\end{array}$ & $\begin{array}{l}\text { No clear central } \\
\text { office role; } \\
\text { state-to-school } \\
\text { project }\end{array}$ \\
\hline
\end{tabular}


At the start of this effort, expectations for central office role could generally be arrayed on the graphic shown above. At the high end of involvement, at least one state envisioned a central office that would be highly involved, glean what the teams learned and accomplished, and disseminate findings to other schools. This would require whatever central office involvement would be necessary to sustain and expand the pilot program. As that state's team leader stated, "This is definitely a district effort... When we extended our invitation, we extended it to a team beginning with the superintendent, the assistant superintendent, and the high school principal. From there they could bring whomever else they wanted" (SL7-1).

At least two other states saw central office collaboration as critical—central office staff would need to actively support the teachers in the effort, might want to participate in learning teams, and would contribute to the work of the teams. Three other states saw the role of the central office as dependent on the nature of the district. In those districts where the school and central-office relationship was quite "tight," (Weick, 1976) the central office would need to be involved. In those where the school had more autonomy, they believed that this program could potentially be run without too much central office involvement.

Three states expected districts to create the conditions necessary for the program to operateallowing release time or flexibility in scheduling — but did not plan that teacher learning teams would need much support beyond that. As one state leader described the involvement, "One of the things that we talked with them about in the initial meetings with the administration is how critical the support of the administrator is, and one of the things that we literally put on the slide in the presentation is that they need to be supportive of the teams, they need to not overload them with other responsibilities, there is a possibility and we encourage an administrator to be an involved member of the learning team. So we really focused on how critical it is to have their support" (SL4-1).

And at least one state viewed this pilot project as a state-to-school project, largely bypassing the central office beyond getting permission to conduct the program. One state leader said, "This project will primarily be school-based. I think the central office person may become a member of the learning team just because of their particular interest, but the intent is that it will be primarily school-based. Our initial interaction was just a way of getting the school selected and the teachers selected" (SL12-1). In some cases, they saw the central office involvement as the inverse of the state-level involvement described in the previous section, though this was not always the case. Seven of the ten generally fell in the bottom three categories represented above, indicating relatively low levels of expectations for the central offices.

In reality, central office activity in this project was very limited. In none of the four districts where we collected school-level data did the central office provide any real support. Interviews with state leaders in the other states have indicated that, with a few notable exceptions, this pattern was quite consistent across states and schools. While district leaders provided some material supports, there were very few cases where the central office professional staff members were involved in the ongoing improvement effort related to this project.

The absence of central office involvement clearly has played a role in teachers' experience of this reform and their ability to meet the implementation goals that were laid out. The lack of coordination between this program and districtwide efforts falls into three categoriesconflicts, pressure, and incompatible systems. 
Teachers working in districts where this program was not supported (and sometimes not even recognized) by the central office experienced conflicting initiatives emanating from the central office. For example, one teacher team reported that they were expected to use a particular rubric for all writing assignments. They did not feel that this rubric necessarily met the writing goals that they were pursuing, nor did it provide the kind of feedback or guidance to students that this project was teaching them would be most beneficial. One teacher explained, "We have so many things being thrown at us to use. Like we have [a commercially available] writing project, but that doesn't particularly lend itself to EAG practices so it's kind of hard. Which one do you want us to use? Because you can't really incorporate both of those." This program encouraged speed and efficiency, but not the sort of descriptive feedback that teachers were learning was important. That same teacher went on to say, "I would rather take a week to grade someone's essay and give it thorough feedback as opposed to 'OK, write me 20 lines and because you wrote 20 lines, that's an A.' To me that's not valuable and I think EAG is trying to create valuable assessments. With [the commercially available product], he's like, if there's 20 lines, no matter what they say, that's an A. I can't do that" (TT5-2). In spite of misgivings, she and other teachers felt pressure to demonstrate that they were using products and techniques that the district had purchased and supported in the past.

Similarly, other district initiatives such as a focus on analysis of summative test score data became conflated with this project so that some teachers were unclear on the relative uses of summative and formative data. Without consistent alignment between central office efforts and this project, teachers generally adhered to district expectations and regarded this project as a lower priority.

Teachers also felt pressure from district leaders to move through course material at a predetermined pace. Several districts have relatively specific curricula and tightly constructed pacing guides (in at least some courses). Some of these district materials include tests and quizzes that are to be given on particular days across the system. Others include benchmarking tests to be given on a particular day and using them as predictive for the final state test. As teachers learned more about assessment through this project, they had problems meshing their classroom-based assessments with the district assessments. Because the materials used as part of this project recommend scaffolding student skills and designing appropriate assessments for each step of the process, the district assessments did not always come at the right time or assess the appropriate goal. Again, teachers felt pressure to adhere to district expectations as opposed to experimenting with the new assessment practices they were learning. One math teacher said, "I have quizzes and tests where it's mandatory that I have to give them on certain days, so I'm rushing to teach certain things and that makes it tough to integrate certain things [that we are discussing in team meetings]." He added: "I try to do assessments on my own, but it's difficult because I know what's on the [districtwide] tests so I try to teach to the tests" so students will be prepared. He felt that he limited student growth in some ways, because "if I focused on higher order questioning, it took away from what they needed to know for the [district] test" (TT6-2).

Finally, some districts have systems with which teachers must comply. For example, at least two of the four districts where I collected school-level data have Web-based systems where teachers put in grades and students and families can see those grades for any given assignment or test. Systems such as these leave no place for comments or descriptions of how one assignment or test may be measuring multiple skills. Though this type of systemic feedback could be supplemented in the classroom with more nuanced and detailed feedback, teachers expressed their feelings 
that such rough indicators undermined the messages that they were beginning to try to send to students and parents. One English teacher in such a system described her conflicts in this area:

I get very frustrated with what I've learned about assessment and my reporting mechanism. The more I learn, the more frustrated I tend to get with my methods of reporting: You know, with whether it be the weighting scale and the use of mid-terms and finals and their weights in there. This idea of the letter grades. What I learned about good assessment doesn't always mesh with what we understand is kind of antiquated, the reporting mechanism that we have. And until there is some sort of adjustment in the reporting mechanism, I feel like I'm banging my head against the wall. Midterms are worth 5\% and final exams are worth $15 \%$ of the final grade. And due to on-line reporting that we have, we have one-day turnaround in order to... for example, the end of our quarter is on Friday, so we have benchmarks that we give our 9th and 10th graders so we know where they are as far as getting them to [the state test]. You give them at the end of the quarter, and then all of our grades are due in percentile form somehow on Tuesday. With midterms, we had a one-day turnaround in order to get it for the parents. I had parents calling me, Why aren't [the grades] online right now? Because [the parents] are ingrained in this old kind of percentile. Well, if that's the case and I have a one-day turnaround, the only way I can do this is if it's multiple choice and a Scantron, and that's not good practice, especially for English. So until something on the other end gives, I feel kind of at a stalemate (TT7-1).

She added further detail of the constraints of the reporting system when she said, "The mechanism that we have automatically calculates averages as opposed to medians which I tend to like to do with achievement grades. If they have a test and I break it down into reading, writing, research, and I have achievement grades, I like to look at medians but our program doesn't allow that, it automatically calculates averages."

Aside from a few exceptions, the role of the central office in this project was given very little attention in most states. Perhaps because relatively few teachers in any district were piloting this new material, school districts did not pay a great deal of attention to the effort and did not make some of the systemic changes that participating teachers would have liked to see. In addition, states, having little experience in providing professional development directly to teachers, were not clear about where the district would "fit" in this new arrangement. As a result, teachers received a host of conflicting messages from the CCSSO pilot project and from their district contexts.

\section{School and School Leader}

If the central office, existing at some distance from the teachers' immediate experience, played a lesser role in implementation of this project, the school context was all the more important. The selection of schools was a key decision that states had to make. States had to devise a strategy for identifying or recruiting schools for participation in this pilot program. States generally partnered with between two and four high schools. As stipulated at the outset, schools had to have significant populations of students who were both low performing and low income. In addition, all states identified schools they perceived to have principals and/or superintendents who would be receptive to the initiative.

In deciding which schools to recruit, states also chose some other attributes, including whether the school had an ongoing and productive relationship with the state through some sort of coaching program, grant program, or other school improvement program run by the state department of education. Many states also wanted schools that were in close physical proximity 
to the state department of education. This was particularly true for those states that envisioned higher levels of state involvement-proximity would, many felt, allow them to be more involved and to monitor the program in ways that would be more difficult with schools at a greater distance. As we will see in the subsequent discussion, this was a particularly prescient decision. Additionally, choosing schools near the state capital and relatively near to one another gave those schools an opportunity to communicate with each other, though this mutual support and networking function was not made explicit in most states. Only four of the ten states described plans for bringing together staff members from participating schools and most of these gatherings happened only once or twice during the course of the project. As one state leader succinctly explained the discretionary approach to connecting participating schools, "If they wanted to work together, they could do that" (SL12-1).

Given these criteria, and the recruiting challenges described in the section of this report on the state role, this pilot project entered into school contexts that were fertile in some senses, but less so in others. For example, in the five schools from which we have survey data, teachers responded with high levels of confidence to the question, "How would you rate your overall understanding of classroom-based assessment practices?" Of 303 responses to this question, 261 teachers or $86 \%$ answered that their level of understanding was "high" or "very high." This would not necessarily imply a great deal of interest in learning about a program that seeks to raise one's level of knowledge around classroom assessment.

When asked about their confidence in particular aspects of classroom assessment, teachers expressed fair to high confidence in areas like giving feedback, questioning students, or communicating goals to students. They ranked their confidence somewhat lower in the areas of involving students or using assessment to build students' desire to learn—both areas that are dealt with in detail in this program. Figure 5 summarizes the teachers' levels of confidence. It is clear that even in particular areas, teachers did not show a lot of hesitation about their skills. The survey responses suggest that the effort to change assessment practices did not encounter environments in which there was a great deal of anxiety around student assessment.

Figure 5. Teacher confidence about assessment practice. $\mathrm{N}=330$.

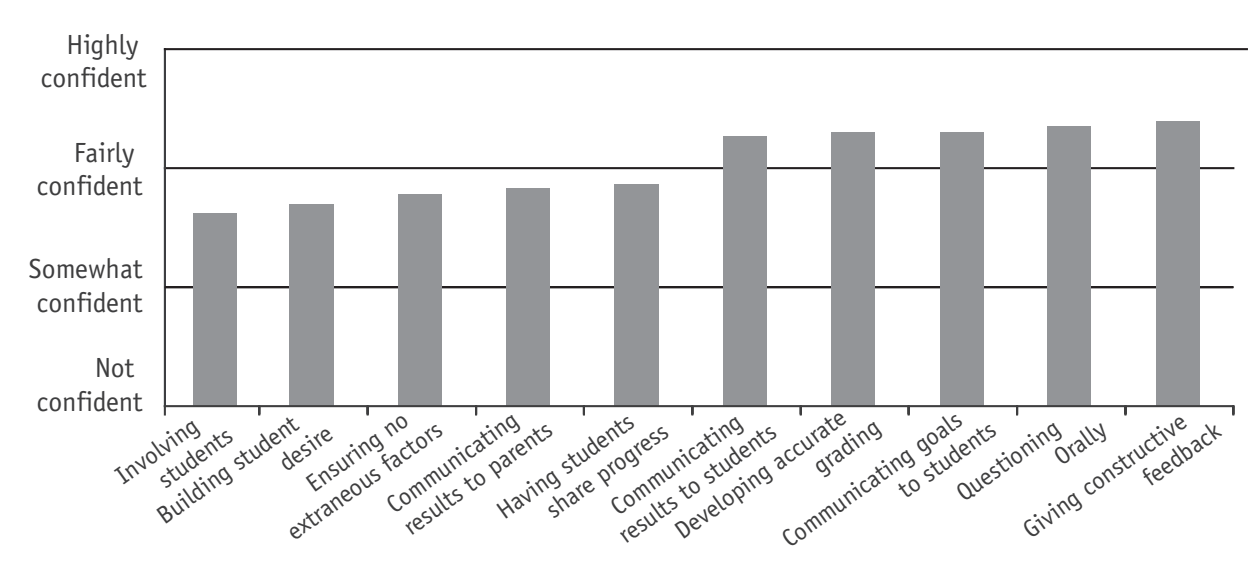

However, there was much more variation in the kinds of assessments that teachers reported actually doing. Teachers reported that they were rarely engaging in many of the practices that 
are encouraged in this program and that could be done with some frequency-activities like having students prepare multiple drafts or having students engage in self assessments. On average, these less frequent practices were happening about once a month. Other traditional practices like classroom discussions or written homework were happening much more frequently. Figure 6 provides a summary of the frequency with which teachers reported they were engaging in a variety of traditional and innovative assessment practices. The data suggest some room for improvement in terms of balancing teachers' assessment practices to include more of the types of assessment recommended in the materials.

Figure 6. Frequency of classroom assessment types. $\mathrm{N}=330$.

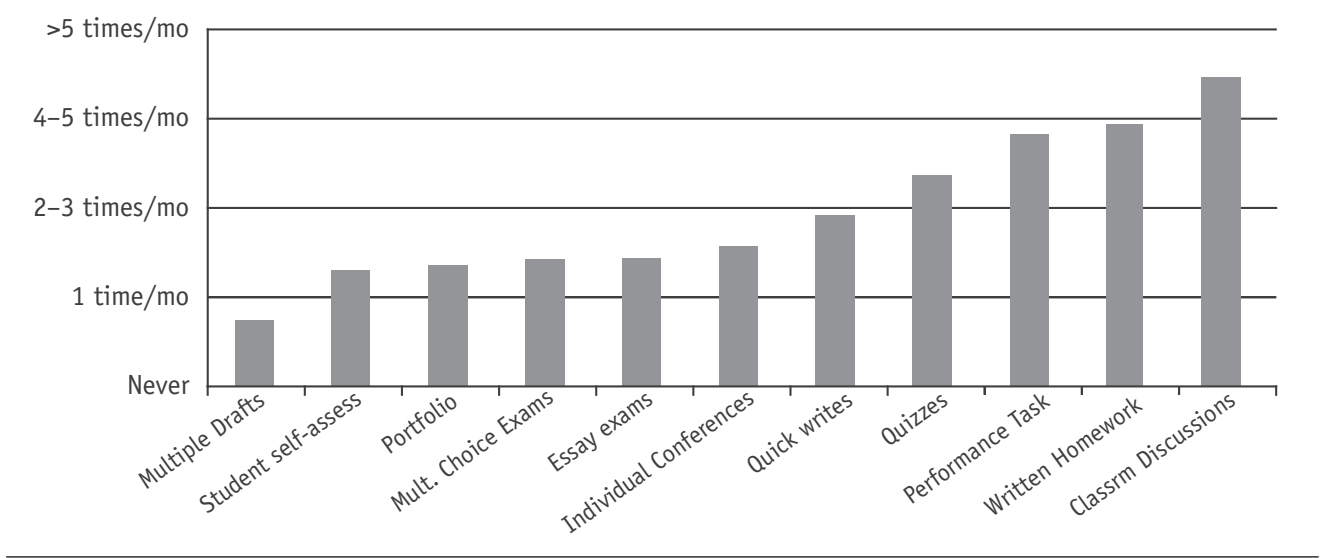

In addition to teachers' potential receptivity to the content of the program being provided, there also was a question about whether the teacher learning team format had the potential to be successful in the schools where it was being introduced. As is evident in Figure 7, teacher learning teams appear to be a particularly promising format. Sources of assessment knowledge that teachers rated most highly included "personal experience" and "teacher teams." These are exactly the mechanisms through which this project works. Teachers are meant to learn material with their teams, try practices in their own classrooms, and reflect on those practices with their teams. It is interesting to note that among seven options teachers were given on the survey, traditional in-service ranks lowest in terms of its perceived utility for teachers. This program explicitly tries to move away from that model by giving teachers control over their own learning. Given teacher predisposition toward teaming and personal experience, the design of this program should have found fertile ground in the schools.

In an effort to describe the apparent contradiction between this somewhat fertile setting and the implementation challenges described briefly at the outset, we must look at the role of the school and school leadership. Clearly some of the reasons for this struggle have to do with the state and district contexts described above. However, the school contexts also posed a number of challenges for the implementation of the program. Two of the challenges that the district posed—conflicts and performance pressure—also manifested themselves, though in slightly different ways, at the school level. In addition, the challenge of scale was raised at the school level.

In terms of conflicts, as at the district level, schools too are trying to institute particular schoollevel initiatives. For example, three of the five high schools were developing common depart- 
mental midterms or finals to be administered to all students at the same time. While some teachers really appreciated this initiative and felt like it gave them an opportunity to work together on crafting a good test, others felt like it forced them to assess in ways that may not be good for them or their students. Situations like these at the school level left teachers uncertain about how to best change classroom practice to meet the needs of both this program and their school's efforts.

Figure 7. Sources of assessment knowledge.

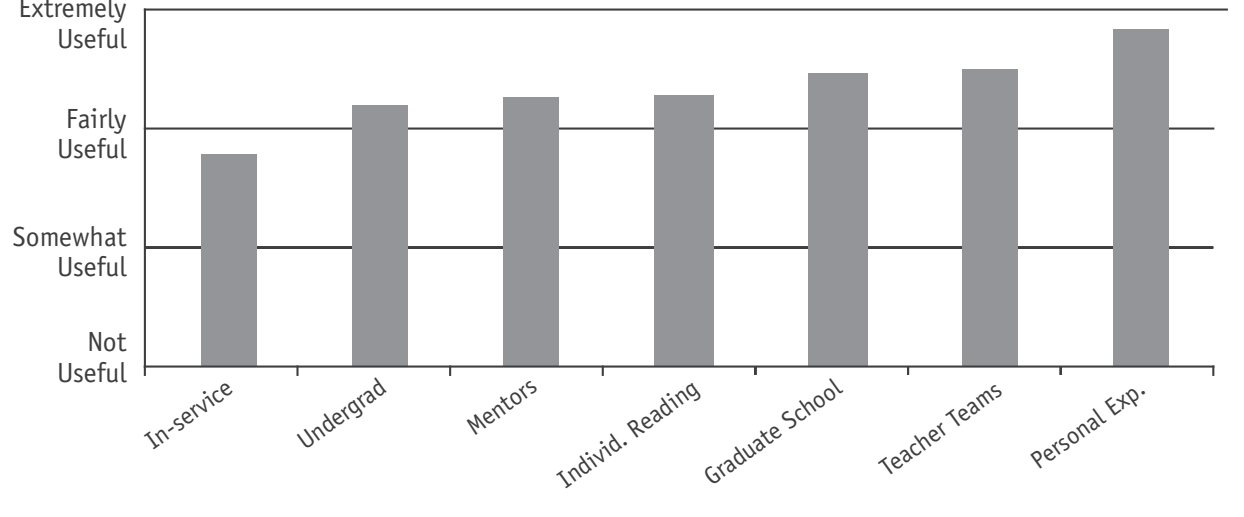

While the district exerted pressure to move through material at a given pace, school leaders exerted strong pressure to demonstrate improved performance on the state assessment. As mentioned, all of the high schools in this study had been identified as low performing based on performance on state tests. Principals and other school leaders both felt and exerted a great deal of pressure for improvement on the state assessment. In many cases, this meant that schools wanted to see tests that look like state tests frequently meaning using multiple-choice items. As teachers learned about using items that are more sensitive to their goals, this caused some dissonance and limited their engagement in more innovative practices. Teachers admitted that they were less likely to try new things in their classrooms prior to administration of the state tests. As one teacher said, "If you come back in a few months, I'll probably be trying lots of these things" (TT8-2). Given this type of accountability pressure, teachers did not always perceive the pilot program to be addressing their most immediate needs. One teacher said school leaders were very focused on preparation for the test and wanted to know, "Did we give the practice test? Did we get the results back? We have these trimester exams that no one seems that excited about, but we have to give them, so we spend a lot of time on that and reviewing that. [Students] have to get 70 so I had to spend a day going over that, and it took two days out of the cycle with a day of review and a day for retest." And while he recognized the benefits of what this program was teaching him, in terms of the state test he said, "In some ways I feel like [this program] could be kind of hurtful because it's kind of slower, make sure the kids understand it and you kind of have to go through more slowly... But at the same time, it does make you focus in more on the important things which can help too" (TT9-2).

Teachers reported that they struggled with this program because they felt like (and were) a minority in their school. "It would be better if everyone were working in the same direction," 
one teacher said. Some felt that the small size undermined the priority of the work. As one principal said, "Because it's so small a grant program in the state, [a teacher] got the impression that it was not a front-burner kind of initiative for anybody. And because of that, I think it makes the teachers feel, why are we doing this? It doesn't seem like a priority for anybody" (PP1-2).

As teachers learned about certain elements of this program, they did not feel as if they could advocate for the kind of system changes in the school or departments that they might like to see. Being so few in number (5-10 teachers in any given high school), teachers felt limited in their ability to make any larger changes and felt that classroom changes would be less effective if not supported more broadly and over a longer period of time. For example, some teachers talked about trying to grade fewer things in place of comments, but felt undermined by school systems and cultures that are very much focused around a grade book or a test with a grade at the top. The small size and limited duration of the program also gave some teachers and leaders a feeling that the effort lacked urgency. A participating science teacher explained, "Anything that's a temporary pilot program tends to get ignored. We have one program here that the school and the district are committed to...so [we're] doing that year in and year out so it becomes part of the fabric of what the school does. Now the EAG, if they continue to revisit it and did a long-term study, they would get better data about how successful it is. Because the idea is really good and I think it has the potential of affecting how institutions do their assessments" (TT10-2).

These three issues of school context impacted teachers' use of and involvement in the program. Some of these conditions could have been ameliorated by strong school leadership. For that reason, we now turn to a discussion of the school leadership for this program to give the reader insight into how principals and assistant principals tasked with leading this effort viewed it.

In short, after the initial kick-off meetings that states held, few school leaders were active participants in this effort. Their familiarity with the materials was generally quite limited. And though several principals reported trying to come to meetings, they generally were not regular attendees. "It hasn't been the number one priority for our team or of any administrator coming to our team saying you guys have to really focus on this. Hasn't been the hot topic this year. Honestly, with the administration, they haven't...we met as our team a couple of times, but we haven't had an administrator come in and say you guys need to focus on this a little bit or just checking up. It's more of an independent kind of feel. The five of us are working together on this team and as long as there doesn't seem to be any major headaches, then nobody's going to bother us" (TT11-1). A state team member who had taken on some school-level team facilitation duties explained the frequent absence of a school administrator in this way, "She has probably spent at least some time in $50 \%$ of our meetings. I do not think she has been in any meeting beginning to end. I don't see that as necessarily a problem or a fault. I know there was one meeting I was going in and I went down to her office-I was going to meet her there to walk to our meeting together-and she was behind closed doors in a discipline situation when I got there, and I finally just said I'll go do the meeting and she was still behind closed doors dealing with the same situation when our meeting ended" (SL9-2). Though she wished for more regular and visible support from school administration, another state team leader acknowledged the competing demands by saying, "Emergencies and the day-to-day priorities of the school, the administrators just cannot ignore those no matter what they intend to do. When those things come up, they have to address them" (SL4-2). 
One principal explained that it was simply a question of the demands on his time. He would have liked to be more involved but had other demands on his time. He said, "We were audited by the state because of our NCLB issues so that's a priority. We have an ongoing discussion with [a national organization] about our accreditation. We're not in any jeopardy of losing our accreditation but whenever you file a report, there's always a subsequent report that comes...there's just so many things that we're focused on all at the same time" (PP1-2).

Aside from this, many principal concerns echoed teacher concerns. They did not feel as if they or anyone else in the school really had the expertise to be facilitating discussions around these issues. School leaders also felt that the state teams that had introduced the program and encouraged them to have their schools participate were not sufficiently involved to really help teachers change. One principal said: "We got off to a very slow start. There was a lot of confusion as far as where we were supposed to get, how we were supposed to get there, what was needed. Though we had an overview, as far as the nuts and bolts, and looking for some direction on how to get this thing moving forward. We really struggled with that. The department of education, they were as helpful as they could be, but we weren't getting much direction from them at the start" (PP2-1). Given the relatively low levels of state involvement early on, principals in several cases took a relatively laissez-faire attitude, supporting their teachers in as much, or as little, as they wanted to do.

Principals also were worried about the amount of time that this program appeared to take for those teachers who were devoted to it. Though school leaders had worked hard to set aside a common planning time for teachers, they also were clear that other things also had to happen during that time - things like parent meetings for those teachers in grade academies, or individual planning, or test prep and analysis. As one principal described the situation, "That was the biggest issue-finding time for them to do it. We had to finagle a couple of things and [we] worked it out [but] the type of kids that they have this year, they have a lot of kids that have some extra needs for support and they're with that kind of group. It's going to take a little more time in the afternoons with parent meetings, and their planning periods are a little more filled up with parent meetings and follow-up in their own planning period to kind of get things done, so it's difficult" (PP3-1).

Principals also were worried about the possibility of scaling up this effort. Given the amount of time they saw some teachers putting in and the limited changes that were happening on the whole, they worried about the feasibility of scaling up this reform within their schools and how amenable other teachers would be to taking on this task and this amount of work. As one assistant principal said about the team in high school: "Other staff members do see these people working like dogs and they're like, 'Wow!' Not everyone's going to want to do that. Thank God we have these guys here" (PP4-2).

In order to accommodate the large amount of time needed to cover the material, one state leader described how her schools had "slowed down to one chapter every three weeks simply because it was putting too much pressure on the teachers. They were not doing a good job because they had too many other things to do. So we said, this is about making this the best that we can make it, and we said what do you want, and they said one every three weeks, and we said that's fine" (SL10-2).

Also, like their teachers, and like participants at the state and district levels, principals were not entirely clear about how this initiative related to other efforts that were going on in their 
schools. They had invested in a host of school-improvement programs that had come with a great deal of support, were multi-year efforts, had experts visiting classrooms, and had all kinds of resources behind them. In comparison, this program seemed relatively limited in terms of scope and ambition. As such, they granted it relatively little attention.

However, in spite of limited principal support and involvement, teacher teams were established and were the structure most immediate to the teacher experience. As stated above, this program is meant to be undertaken by a volunteer team of teachers (and administrators in some cases) who wish to improve classroom assessment. We now turn our attention to the design and function of these teams.

\section{Teacher Learning Team}

The composition of teacher learning teams varied across the states and schools. At the outset, states articulated different visions of learning team composition. Some states explicitly wanted to send a message about how the strategies in this program could be used across subjects and grades in high school and for this reason asked schools to create interdisciplinary learning teams. Other states wanted to target grades or subjects where high schools in their states had faced particular challenges in helping students to meet standards. These states asked schools to create subject or grade-specific learning teams. In reality, once confronted with the challenge of recruiting schools and teachers, states allowed individual schools to choose how to best compose their learning teams. Often this meant that the program was added to the work of teams that already existed in the schools. Frequently, this made logistics easier in terms of finding common planning time or using other structures already in place. It is worth noting that in none of the focal high schools or any of the other schools in the project (based on the reports of any of the state leaders), did this program make use of the pre-existing subject department structure in high schools. It is not entirely clear why this decision was made-perhaps the initial inclination to include only volunteer teachers played a role-although the choice of how to configure teams was most frequently made at the school level.

Regardless of the path, the composition of the team posed at least six challenges for the teachers:

1) finding a common language to talk with peers,

2) changing the traditional functions of teams,

3) facilitating rich discussion,

4) changing the focus from teachers to students,

5) dealing with teacher turnover, and

6) finding sufficient time.

Each of these challenges related to team context is described below.

Almost all of the teams that exist in this project are interdisciplinary, meaning that teachers on the teams come from a range of subject matter departments. In these teams, there often is only one teacher with a particular content expertise. Teachers in this situation stated that they would like someone with similar content expertise with whom to collaborate as they seek to achieve certain program goals such as making standards or goals clearer or asking better content-based questions. This is a particular challenge at the high school level. In these interdisciplinary groups, teachers frequently felt discussions were somewhat limited and that they could not ask 
questions that they felt were at the heart of their challenges. One science teacher who was on a team with English and special education teachers described the situation in this way: "Having the same content area would be a benefit...I had the benefit of having taught English for a couple of years so I could relate to what they were doing. But we never really did any science stuff. I kind of went afterwards and related back to it, and I really do wish that I could have brought it to the table, and it's not that they wouldn't have done it. It was just easier for group dynamics to stick with the English stuff, although for one thing we did with questioning, I was the facilitator and we did use a science piece, but it was part writing and part an essay, so it was back on their level and the questions were a basic-level science so they could really relate to it" (TT12-2). Alternatively, other teachers felt that having a diversity of perspectives was good for their teams, providing viewpoints more similar to those of their students who may lack familiarity with the discipline.

As stated above, teacher teams in this project frequently were already established in the schools. In schools where this program was incorporated into pre-existing teams-most often grade-level teams - those teams had their own previously established agenda and procedures. Bringing in this program with a particular idea of how learning should move forward—-that is, study, try, discuss, revise-frequently did not fit with what the teams were doing. For example, one ninth- grade team had spent considerable time meeting with individual students to have them develop goals for themselves and monitoring progress toward those goals. Having established this practice the previous year and feeling that it yielded some success, teachers were loath to give it up in favor of this new program.

Once teams were established, teachers expressed confusion early on in the process about the role of the facilitator and spent considerable time negotiating the process for meetings.

Though there is a guide for team facilitators, teams got that text later than other material and often did not feel as if they had time to look through both that text and the CASL text. In initial interviews, teachers said they would let the facilitator role rotate in order to share the work. In fact, by the end of the school year, only one of the five schools had a team in which the facilitator role rotated. The others had one member who took on the facilitator role. In one case, this role was being filled by a member of the state team.

For teachers both with and without group experience, many reported spending a great deal of team time focused on individual students. Based on a sincere desire to help the most struggling students, teams focused on talking about challenges faced by those students and what could be done to help individuals. The focus of many teams was to address individual concerns, rather than instructional changes that might help larger numbers of students. This was particularly true for grade-level teams that had common groups of students. In the focal schools, teachers were asked to estimate how much time teams spent talking about teacher work and practice. The highest estimate from the teachers was $25 \%$ with most being significantly lower.

Another challenge related to establishing a highly functioning team is the high degree of teacher turnover. This is particularly true in low-performing schools, such as those in this study. Teams did not have a clear strategy for dealing with the departure of one member and the arrival of a replacement. If a team is progressing through material, what do they do when a replacement arrives and has to catch up? Teachers could not answer this question. In one school, $40 \%$ of the team turned over between the start of the effort at the end of the 2006-07 school year and the midpoint of 2007-08. Because a team is meant to work on common material at 
the same time, a new arrival with little knowledge of this type of classroom assessment posed a huge challenge for team functioning. There was no clear strategy for dealing with this challenge.

Even if teams were able to address all of the five challenges identified above, one of the most common constraints was finding a mutually agreeable time for the team to meet. In some schools, a common meeting time was factored into the schedule. In other schools, it was additional time for which teachers got paid. However, in both of these cases, there were many examples of times when teachers were pulled out of their meeting time to fulfill some other obligation. For example, where teachers had common planning time during the day, they sometimes had to cover absent teachers' classes, or meet with a parent about a particular issue, or attend to any one of a host of other duties. For those teams that met after school, there often were athletic or extracurricular conflicts, family issues that needed attention, or scheduling challenges that made meeting impossible. A lack of sufficient meeting time was the single most common constraint cited by teachers in identifying impediments to the successful function of their teams. "We knew we were supposed to be meeting, but our lives are busy so we haven't really. It's hard for teachers to just say, we're going to sit down and do this without having somebody who's expert. Or even assigning a team leader from day one would have been insanely helpful" (TT1-1).

\section{Teacher}

In addition to larger institutional issues, teachers had some individual-level challenges in implementing this program. First among these may be the fact that many of the teachers in our focal schools were not really volunteers. A teacher in one school said, "We didn't volunteer. They presented it to us and they asked us if we wanted to do it, and we said no and we were told we had to do it. They picked us because we are the two teams of the Freshmen Academy." A teacher at a different school, who had tried to continue to work the program while many of her teammates did not, felt that the lack of being a volunteer was a serious problem: "I know there were a couple on my team that were directly asked. [The principal] said, 'I want you to be a part of this.' So they weren't there because they voluntarily wanted to do it, but yet there wasn't any accountability for them. So that meant if they could get by without having to do it, they were going to" (TT4-2).

This program is designed for volunteers. Teachers are meant to be self-motivating. In the focal schools, in many cases principals or other school leaders cajoled or commanded teachers to take part. Or, as mentioned above, this responsibility was added as a responsibility onto a preexisting teacher team. This fact is a major departure from the program design. However, this strategy did not backfire in all cases. One long-time teacher who was asked to be part of the team candidly said, "I'll be honest with you. When I was first asked to do this, I thought it was stupid. But after I got into the material and I understood the difference between assessment for and assessment of learning, I said, wow, this really makes sense and I really think there's a lot to be had here" (TT13-2). Even where teachers had little familiarity with the program, the teachers who had heard about it or flipped through the book were generally positively predisposed to the materials. They expressed a commitment to helping students to succeed and if they can be convinced that this will play a role in that, they are willing to try it with the proper supports. They particularly liked the idea of addressing student motivation-a commonly stated problem-and were attracted by the idea of knowing more about what their students really know. 
For more experienced teachers, this program asked them to both recognize and share with peers, and often state department leaders, the things that they do not know. Even without some of the team conditions described above, this kind of public disclosure was a very difficult thing for teachers. Additionally, it is often hard to recognize or identify the things we do not know. For example, one teacher said, "There may be particular areas that the kids struggle in that I don't recognize right now." Another teacher, who had made some progress in the program, said, "I always knew that students were afraid of tests. I just didn't know they shouldn't be" (TT13-2).

Finally, as at the team level, finding sufficient time was a huge issue at the individual level. Teachers reported not having the time to go through the material on their own. Though the material developers stated at the state training that this program would take as much time as a regular graduate course, this message was not conveyed to or did not register with teachers. Teachers were not prepared to do the reading or video watching on their own time. Instead, this preparation frequently happened during group meetings and, as such, limited the amount of time for discussion.

While limited time had implications for individual mastery of the content of the materials, a couple of teachers also raised the issue of not having sufficient time for this process to unfold. One teacher provided an example of how he would like to improve practice over the course of two to three years:

It's a difficult thing to put in place instantly in one year because you may change slightly what you're teaching to come up with a student-friendly learning goal... You put up a goal like 'Learn the Pythagorean theorem,' but they don't know the word. And particularly in the inner-city schools, their vocabulary is relatively poor, so words like adjacent they don't know and you're just amazed that the whole class does not know words that you sort of take for granted. So from a teacher's point of view, you can write what you believe are studentfriendly terms and it's not. It really has to be field-tested. It has to go in front of your students, your class, and see if they know what you're talking about... To me, it's something that's going to take two or three or more years of active attempts so that you can put it up there so they have a good idea of what they're supposed to be learning before it's taught (TT14-2).

Some teachers did not feel that there was sufficient recognition of the amount of teacher time it would take to enact changes in the classroom. For example, giving more feedback, or having students give more information about how they are feeling about their progress, and trying to incorporate that information into instruction and planning are practices that teachers spoke of as taking significant amounts of time to incorporate. 


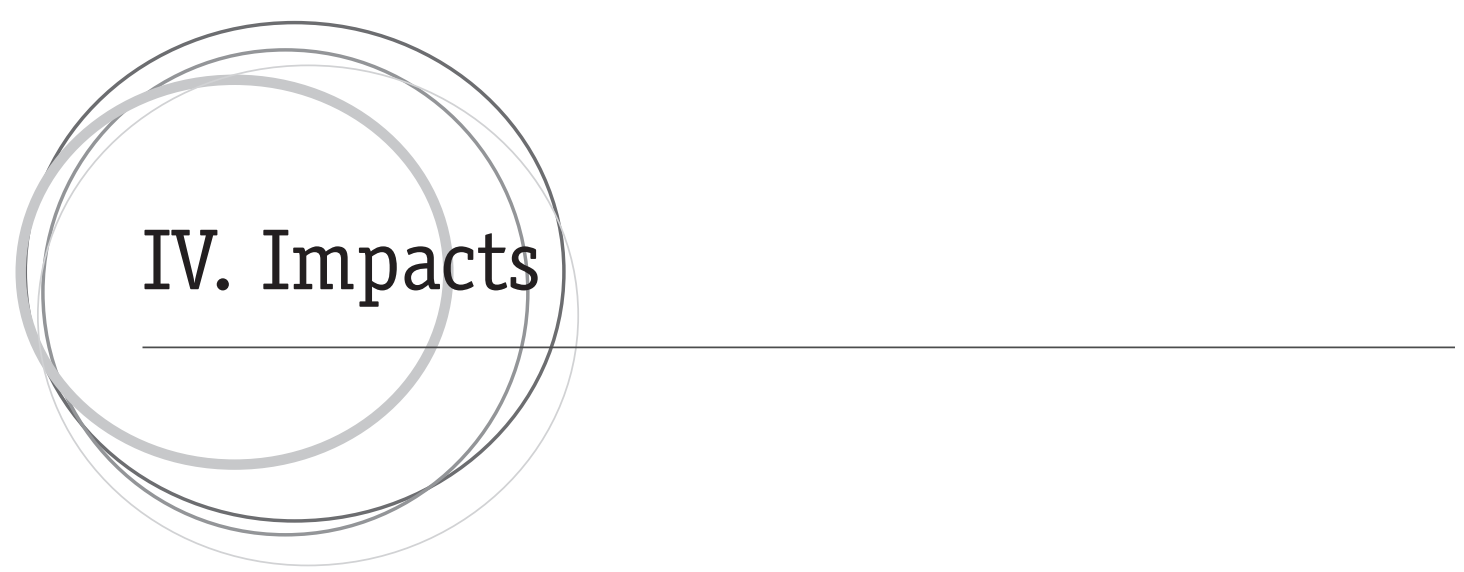

At the midpoint in the year, it appeared that there were a few teachers (six of the 40 interviewed) who reported that they had tried various strategies described in the program materials and could report success from their use. Due to challenges at the state, school, team, and individual levels, implementation had proceeded much more slowly than project planners had hoped. The teachers who had begun to engage with the materials reported giving more feedback to students, or having them monitor their own learning, and could see effects of this in their classrooms. They reported that students were increasingly eager for feedback and engaged in their classes. Those teachers were mostly using the book as a resource, picking and choosing pages where they saw fit, or because they felt they should make some use of it. They largely had not approached these materials as a guide to fundamental change in classroom operation. Only one team reported making any use of the DVDs and none of them reported using any of the supplemental texts or the other learning opportunities that the program has provided.

By a point later in the spring, much had changed. Many more of the teachers who were still involved with their teams could point to at least one strategy that they had tried in their classrooms and that had appealed to them as a worthwhile practice. In spite of the many implementation challenges described above, there is some evidence that this pilot program was beginning to have an impact on teacher practice. This evidence all comes from the final round of data collection, which occurred in the spring of 2008. Addressing all of the startup challenges described above took much longer than anyone had anticipated. Leaders at the state and school levels regularly expressed their surprise and dismay that progress had not been made more quickly.

However, given these constraints, many teachers, even among the most reluctant participants, did report some change. For example, one teacher, a facilitator of his high school team, stated that there had not been many meetings and "the EAG grant hasn't really factored into it." However, he then went on to describe a system in which "we came up with an idea where the students would indicate their confidence in a particular answer. I want to know basically, did they guess, or they thought they knew it and it was wrong, or they knew $100 \%$ it was right. So, from that we're getting a couple of things. If the kid thought it was 100\% right and it was wrong, now we have to ask the kid, how did that happen? The other one was if you're guessing at it and 20 other kids are guessing at it, there's a gap there in how the material was taught or what my expectation was ... We've eliminated questions because how can you grade the class down if $50 \%$ were just guessing." In fact, this practice of helping students to gauge their own confidence in their answers is suggested explicitly in the project materials and this teacher later recognized that "that may have come from the [CASL] book, I don't remember where we got that particular strategy" (TT15-2). 
There were many other examples of changes that teachers began to try in their classrooms as a result of their participation in this project. For example, one team had begun a real focus on pushing students to assess their own work. As a teacher described the approach: "The students every day in our [classes] have to self-assess themselves. They have to score themselves points and they also have to give themselves comments, and then we comment back to them so there's descriptive feedback daily in that regard" (TT8-2). Another teacher spoke about diversifying the types of questions that she used in assessments to allow students to choose how they could best convey their learning in her class.

But no aspect of the materials was mentioned more than the use of "student-friendly language." Some participating teachers in every school, even those where use of the materials had been minimal, spoke about trying to be more attentive to putting standards, expectations, questions, or feedback into language that their students would more easily understand. As one teacher said after engaging students about what they understood and didn't: “I never realized that some of my students didn't even understand the comments that I was putting on their papers." Though this process had just begun for many of the teachers, and they did not feel entirely secure in their ability to meet this goal, it was clearly an idea that many found compelling.

One teacher summed up her experience with the program this way:

Whenever you're trying to make change, especially in your classroom, the work falls on the teacher. That is the nature of our profession so I think we all feel as team teachers that it's a huge undertaking. And of course there are days when you're like, "God, why do I have to do this?" When we first heard about this, it was like one more thing on the plate. When does this stop? But, like I said, we do feel that there are valuable pieces to this. I'm becoming a better teacher for it. Change takes work. It would be nice if it didn't. The student excitement and energy is the payoff. That's the profession. You work, you work, you work, and it's for those moments. I feel it will get easier once I'm comfortable and I know at the beginning of next school year how to run a writing portfolio, for example. I can probably start grading less and less earlier in the school year. First term it's going to be me, second term you're going to switch, third and fourth term you're grading yourselves. So [I'll] kind of know what steps, have steps for myself. A lot of this is do, reflect; do, reflect; that didn't work, let's go back (TT16-2).

While the qualitative data give some evidence of changes in teacher thinking and practice, the survey data show less robust results. For example, a survey question asking teachers to identify teacher comments as either evaluative or descriptive showed no change between the two urvey rounds. (Please note: All of the data presented from this point forward relates only to the 26 teachers participating in learning teams for whom there are survey data from both years.) So while in interviews teachers certainly spoke more about the importance of descriptive feedback, the five items on the survey did not demonstrate a change in assessment knowledge among teachers on the learning teams.

Similarly, the levels of confidence among participating teachers about classroom assessment did not change significantly (Figure 8). While there were no significant changes evident from the survey, in combination with interview data from teachers it may be possible to see teachers feeling more confident in using assessment to build students' desire to learn, communicating goals to students, and involving students in goal setting. All of these are areas about which teachers spoke of having learned more as a result of this program, as described in previous sections on teacher response. 
Figure 8. Changes in teacher confidence. $\mathrm{N}=26$.

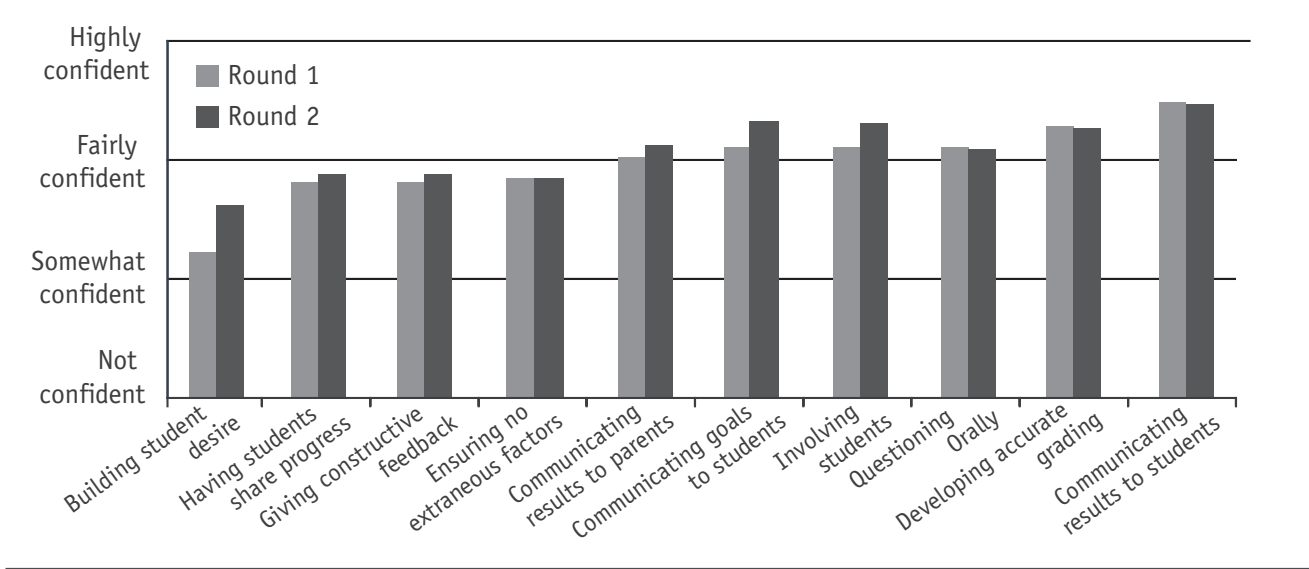

Neither were there reports of dramatic changes in teacher assessment practice on the survey of participating teachers (Figure 9). There was some small growth in reports of using student self-assessment, extended response, and classroom discussions as means of measuring student learning. All of these are assessment alternatives suggested in the materials used in this project. There also is growth in the use of multiple-choice exams. This may be due, in part, to the pressure that teachers reported feeling, discussed earlier, to create exams that looked like the state assessments. The second round of surveys was administered after the participating schools were under another year of scrutiny for their test performance. It is likely that this external accountability pressure encouraged some teachers to make use more frequently of the traditional exam types that mimic state tests.

Figure 9. Frequency of assessment types. N=26.

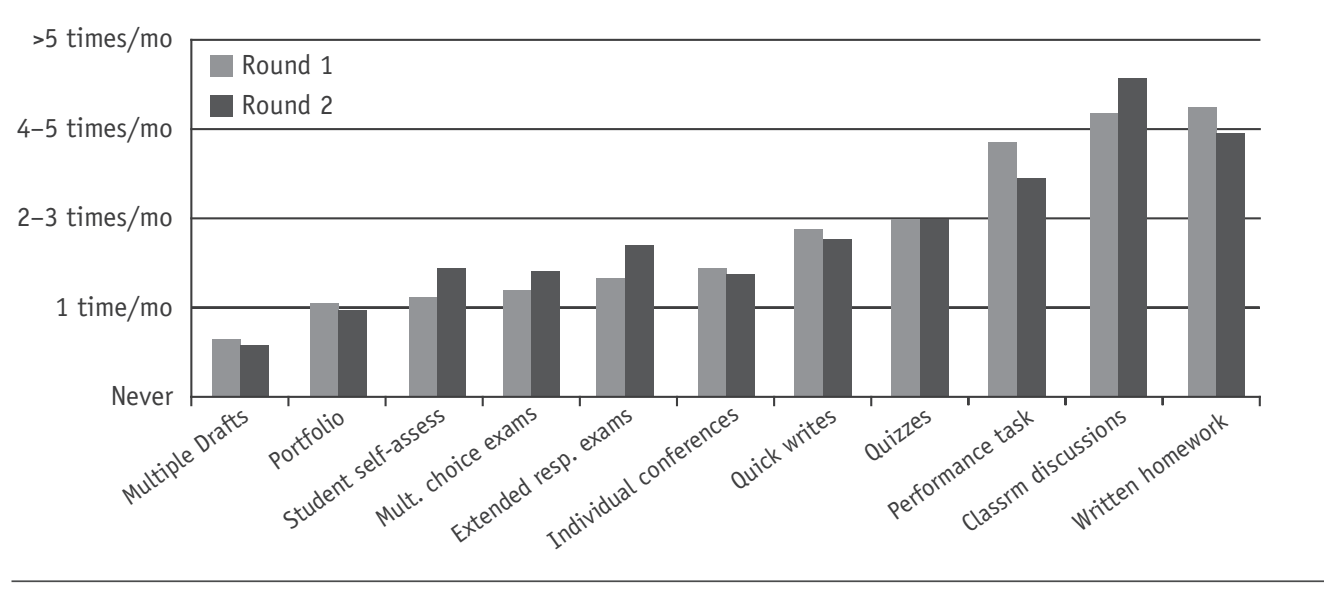

A more nuanced look at changes in teacher assessment practices conveys a similarly stable picture (Figure 10). However, there are some encouraging signs of change. For example, teachers reported that they were less frequently assigning grades to practice work. This indicates that some had 
assimilated the idea that practice was meant as an opportunity for feedback and learning, not grading. Teachers also were less frequently considering student effort when assigning grades for achievement, were feeling less compelled to ensure that all multiple-choice questions had the same number of options, were less frequently limiting the possible number of A's on any assignment, and were less frequently viewing letter grades as the best way to provide feedback to students. All of these changes represent improvements in so far as teachers reported doing certain things less frequently-those that the program teaches are not likely to help student learning. Figure 10 shows that in many other areas, there was little change in teacher behavior.

Figure 10. Assessment practice. $\mathrm{N}=26$.

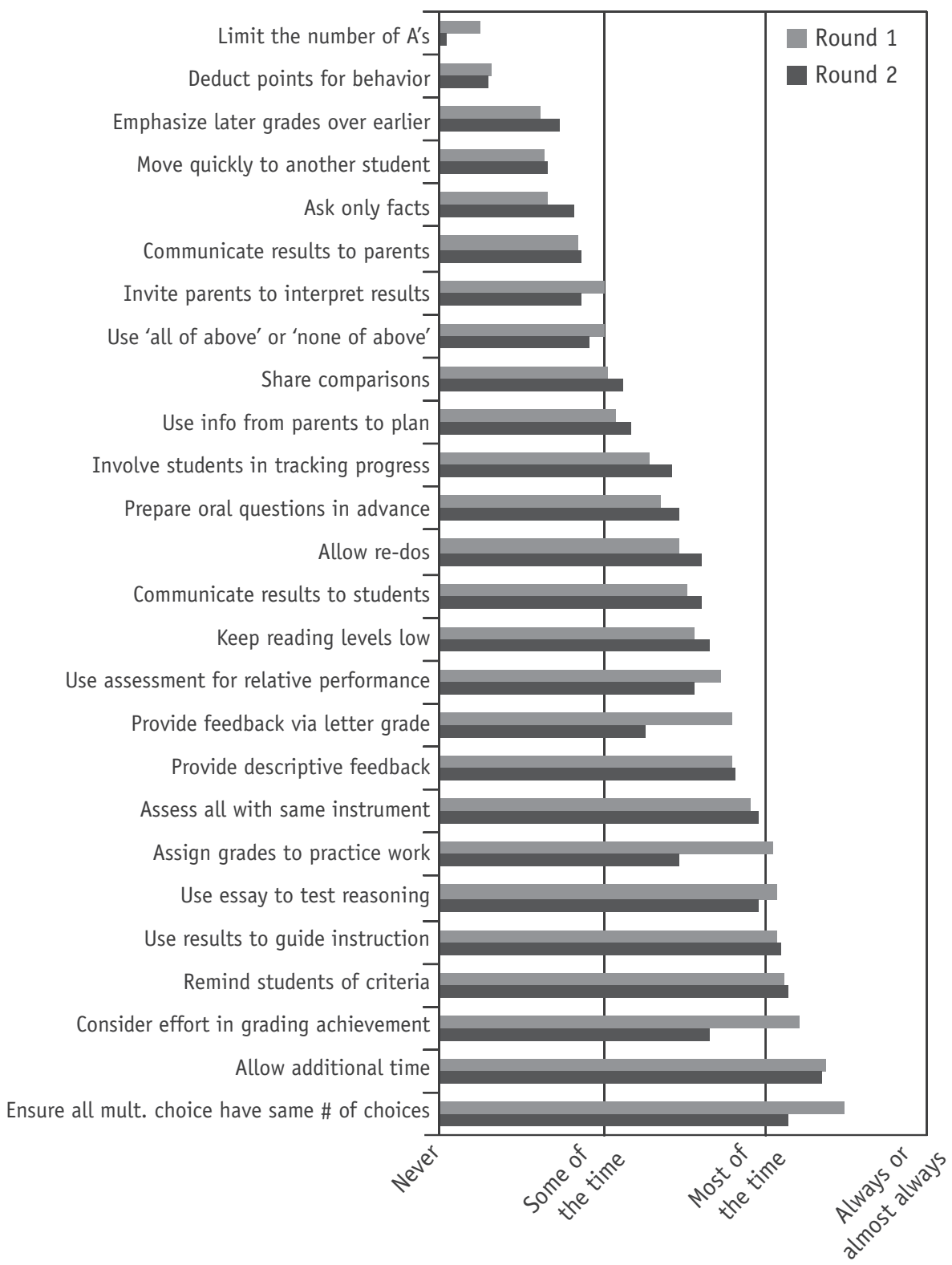




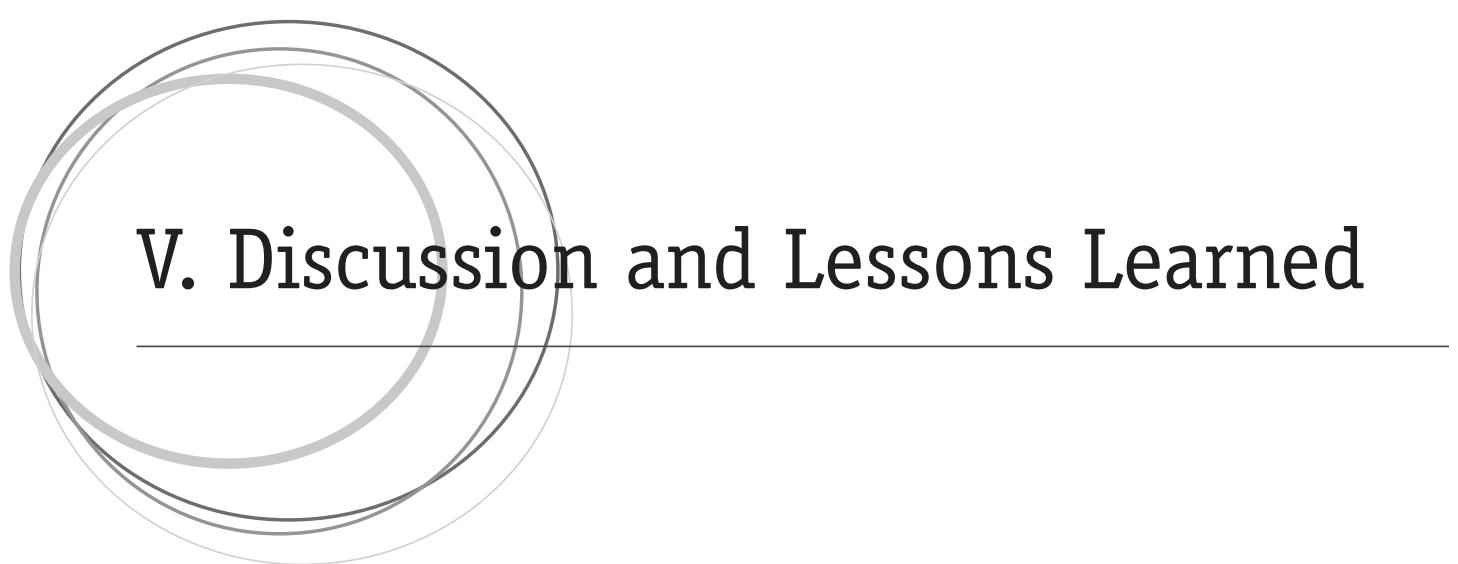

The findings and impacts from this study raise several important points for those seeking to implement and support a school improvement program. Following the framework established in this report, we now turn to a discussion of the challenges faced at each level of the system and lessons learned from those experiences.

\section{Lessons for the States}

As mentioned at the outset, this evaluation was meant to serve both formative and summative purposes for this project. As part of that effort, findings and impressions from the ongoing data collection were shared with project participants throughout the course of this project. Resulting in part from the sharing of interim findings, the behavior of state teams changed significantly over the course of this project. The project also built on some of the more successful cases by sharing information among team members. The conference in the summer of 2007 and periodic Internet-based meetings allowed state teams to hear what others were doing to support their schools. This experience alone should recommend the use of pilot programs and formalized ongoing evaluation as a means of addressing challenges and engaging in constant program improvement.

As a result of the limited implementation early on and many of the challenges discussed at the start of this report, state teams in many cases increasingly became involved in school-level efforts. They sent people to the schools to work closely with the teams. They set agendas and looked for examples of teacher work that they could share with the school teams. They were a much more regular presence in the schools than they had been at the start of this effort. In part, this required a shift in the use of state capacity. The limited time, attention, and expertise that most state leaders had to devote to this project constrained the support that they were able to offer initially. Over time, state teams were able to address these limitations by building expertise (human capital), building relationships among state team members and with other resources (social capital), and shifting some responsibilities to make time available for direct interaction with the schools (physical capital). Without this infusion and reconfiguring of capital, support for the schools would not have been possible.

States appear to have been somewhat uninformed about previous research about what is required to stimulate productive teacher learning teams and subsequent changes in teacher practice. Provision of well-crafted materials and an enthusiastic introduction will not suffice. In interviews with state leaders, the most commonly cited success of this project was a newfound recognition of the resources and support needed for successful professional development. In a context in which states increasingly are being called upon to assist schools that they identify as low performing, these lessons are crucially important. 


\section{Lessons for the Central Office}

In the vast majority of cases, the district or central office was not a significant player in this effort. In the few cases where a central office staff member participated in the work of teacher teams, it imbued the entire effort with a level of importance and recognition that state leaders reported as being helpful in sustaining the work. However, in most cases, the absence of central office participation caused project participants to have difficulty negotiating how to fit this improvement strategy in among others. Central office involvement would have accomplished at least two things: provide important symbolic support for this effort and potentially begin to help the system as a whole to wrestle with how to incorporate new assessment ideas into the work of teachers.

It is telling that few state teams went out of their way to involve central office leaders. Though central office staff members were involved in the decision to introduce this program and make it available to teachers, there was little involvement beyond that. The potential support that could be offered at the local level though participation of central office staff was not recognized in most cases.

\section{Lessons for Schools and School Leaders}

As was true for the central office level, school level leadership had the potential to make a significant difference in the work of teacher learning teams. Those teams that experienced direct involvement of a school leader were more focused and directed in their work. The presence of such an individual demonstrated that the work being done during team meetings was important and valued. In fact, such individuals were according to state leader report, involved in a minority of the teacher teams. Among the five focal high schools, the principals were all quite rhetorically supportive of the work of the teams. However, in none of those schools was an administrator directly involved in the work of the teams from the start. This absence contributed to their shaky start.

\section{Lessons for Teacher Learning Teams}

Teacher teams benefited greatly from the guidance they received, delayed though it was, about facilitating productive meetings. This finding indicates that the process of teacher learning teams engaging with material is as challenging as the content. Aside from the various challenges articulated in this report (finding common meeting times, conflicts with state and district initiatives, understanding project goals), respondents at all levels discussed the amount of time it took to create a pattern that led to productive meeting times. Few teachers had participated in teams where the goal was teacher learning (rather than administrative or programmatic changes) and modifications to classroom practice. They were not prepared to set realistic goals, to engage in meaningful discussion and critique of each others' work, and to create the encouraging and trusting environment necessary for professional growth. The knowledge about how to work as part of a learning team was not clearly understood by many participants at all levels early in the experience and would have provided a stronger base for many teams to build upon.

Learning teams also struggled with how to balance the generic instructional pieces that they were learning from the materials with their subject-specific challenges. Most teams in this study included teachers from a range of subject matter areas. As discussed above, this provided 
both benefits and challenges in team discussion. While teachers became more attuned to the ways in which they could gather information about their students' learning, the teams did not provide fertile ground for discussions about how to take the next step to address the learning gaps that may have been identified. Teachers must have venues for learning not only how to identify goals and gaps more effectively, but how to address those within their areas of expertise.

\section{Lessons for Teacher Involvement}

Teachers interviewed for this project generally expressed support for both the general ideas of this project as well as the specific materials. However, in spite of this, there was reluctance on the part of many to participate. Among many teachers, this was rooted in a feeling that they did not have sufficient time to embark on another project. Related to this was the sense that no one at the school (other than the teachers themselves) had a picture of how many things they were being asked to do. Among some teachers there also was the feeling, as evidenced in the survey data provided, that teachers were fairly confident about their assessment expertise. The challenge then, to encourage greater teacher investment in this effort is to (1) identify where this effort fits among all of the other professional commitments that teachers are being asked to make and (2) demonstrate how the new material being introduced will enhance or build upon the knowledge and skills that teachers bring to their work.

While many of the ideas were new to participating teachers, according to their own reports, there were opportunities to make connections to their own pre-existing knowledge (although such connections were not often made explicit). As teachers began to discover these connections for themselves, their confidence and interest in the material grew.

\section{Concluding Thoughts}

As mentioned at the outset, traditional uses of assessment dominate in schools. Innovation requires expertise and time and space for experimentation. These commodities were in short supply in this project. None of the regular participants were well-versed in the concepts and strategies being promoted in the program. And participants at many levels expressed concerns about the time and organizational "space" (i.e., the place of this effort within the context of other ongoing efforts) devoted to this program. The examples of changes that were in line with the program expectations often came in spite of these constraints. They were the products of individual teachers or state leaders who assumed strong leadership roles within teacher teams.

In large part, this is a story of how difficult it was, even with high-quality materials and eager state (and sometimes school) participants, to change assessment practices. Though school teams were formed in the spring of 2007, many teams did not really begin to work with the materials until the fall of 2007. It then took a few months for teams to confront particular challenges and for state teams to intervene to help address those challenges. State teams began to be more proactive at the start of 2008 and were then somewhat stymied by the all-consuming nature of state testing, which occurred in the spring in most states. Those teacher teams that persisted through the first half of the year were beginning to report trying some new practices in their classrooms just as the school year was winding to a close.

We would not expect a surgeon to convene a meeting of co-workers, discuss how to do a particularly complex surgical technique, and then expect every attendee to execute the technique 
flawlessly working alone in an operating room. We would not introduce a new technique without discussing how it may be related to all of the other medical concerns that must be attended to in the course of surgery. Yet we regularly ask teachers to do something analogous. In some ways, this project attempted to break out of that mold by providing ongoing collegial support and encouragement to teachers in addition to introducing the principles of assessment for learning. However, the kind of intensive and ongoing collaboration and feedback that is required to help teachers to integrate new ideas and practices into pre-existing routines had yet to be recognized and realized in all sites. 


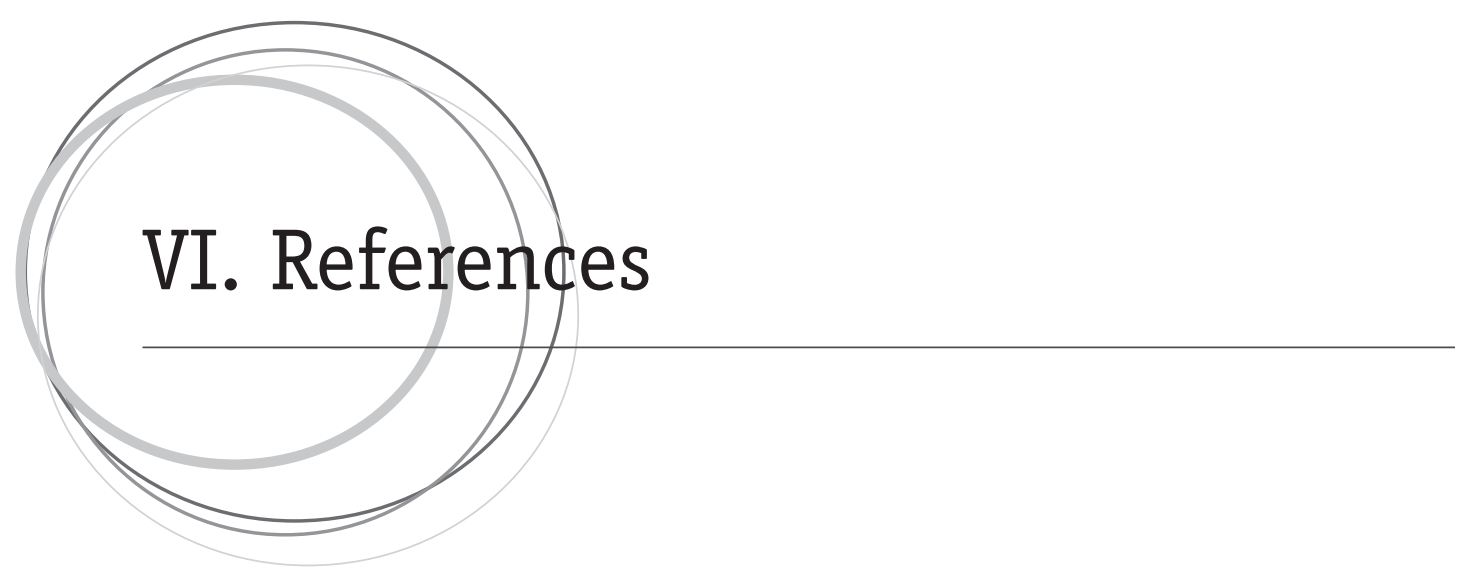

Black, P., Harrison, C., Lee, C., Marshall, B, \& Wiliam, D. (2003). Assessment for learning. Berkshire, England: Open University Press.

Black, P., \& Wiliam, D. (1998). Assessment and classroom learning. Assessment in Education: Principles, Policy \& Practice, 5(1), 7-75.

Butler, R. (1988). Enhancing and undermining intrinsic motivation: The effects of task involving and ego-involving evaluation on interest and performance. British Journal of Educational Psychology, 58, 1-14.

Cohen, D. K. (1982). Policy and organizations: The impact of state and federal educational policy on local school governance. Harvard Educational Review, 52(4), 474-499.

Crooks, T. J. (1988). The impact of classroom evaluation practices on students. Review of Educational Research, 58(4), 438-481.

Crow, G. M., \& Pounder, D. G. (2000). Interdisciplinary teacher teams: Context, design, and process. Educational Administration Quarterly, 36(2), 216-254.

DuFour, R., \& Eaker, R. (1998). Professional learning communities at work: Best practices for enhancing student achievement. Alexandria, VA: Association for Supervision and Curriculum Development.

Dweck, C. (2001). Self theories: Their role in personality, motivation, and development. Philadelphia: Psychology Press.

Educational Testing Service. (2008). http://shop.assessmentinst.com/servlet/ProductView? command $=$ cp \&supplierID $=649 \&$ commodityID $=17165 \&$ searchIndex $=0$ Accessed 19 February 2008.

Lévi-Strauss, C. (1963). Structural anthropology. Trans. Claire Jacobson. New York: Basic Books.

Lipsky, M. (1980). Street-level Bureaucracy: Dilemmas of the individual in public services. New York: Russell Sage Foundation.

Little, J. W. (2002). Locating learning in teachers' communities of practice: Opening up problems of analysis in records of everyday practice. Teaching and Teacher Education, 18, 185-192.

Marzano, R. (2003). What works in schools: Translating research into action. Alexandria, VA: Association for Supervision and Curriculum Development.

McLaughlin, M. (1976). Implementation as mutual adaptation: Change in classroom organization. Teachers College Record, 77, 339-351. 
Pounder, D. G. (1999). Teacher teams: Exploring job characteristics and work related outcomes of work group enhancement. Educational Administration Quarterly, 35, 317-348.

Quinn, G., \& Restine, L. N. (1996). Interdisciplinary teams: Concerns, benefits, and costs. Journal of School Leadership, 6, 644-660.

Sadler, D. R. (1989). Formative assessment and the design of instructional systems. Instructional Science, 18: 119-144.

Spillane, J. P., Reiser, B. J., \& Reamer, T. (2002). Policy implementation and cognition: Reframing and refocusing implementation research. Review of Educational Research, 72(3), 387-431.

Stiggins, R.J., Arter, J.A., Chappuis, J., \& Chappuis, S. (2006). Classroom Assessment for Student Learning: Doing it Right, Using it Well. Portland, OR: Educational Testing Service.

Supovitz, J. (2002). Developing communities of instructional practice. Teachers College Record, 104(8), 1591-1626.

Supovitz, J., \& Klein, V. (2003). Mapping a course for improved student learning: How innovative schools systematically use student performance data to guide improvement. Philadelphia: Consortium for Policy Research in Education.

Thomas, G., Wineburg, S., Grossman, P., Myhre, O., \& Woolworth, S. (1998). In the company of colleagues: An interim report on the development of a community of teacher learners. Teaching and Teacher Education, 14, 21-32.

U.S. Department of Education. (2008). Grants for Enhanced Assessment Instruments, Program Description. On the web at: http://www.ed.gov/programs/eag/index.html Accessed 1 August 2008.

Weick, K. (1976). Educational organizations as loosely coupled systems. Administrative Science Quarterly, 21.

Wineburg, S., \& Grossman, P. (1998). Creating a community of learners among high school teachers. Phi Delta Kappan, 79(5), 350-353. 

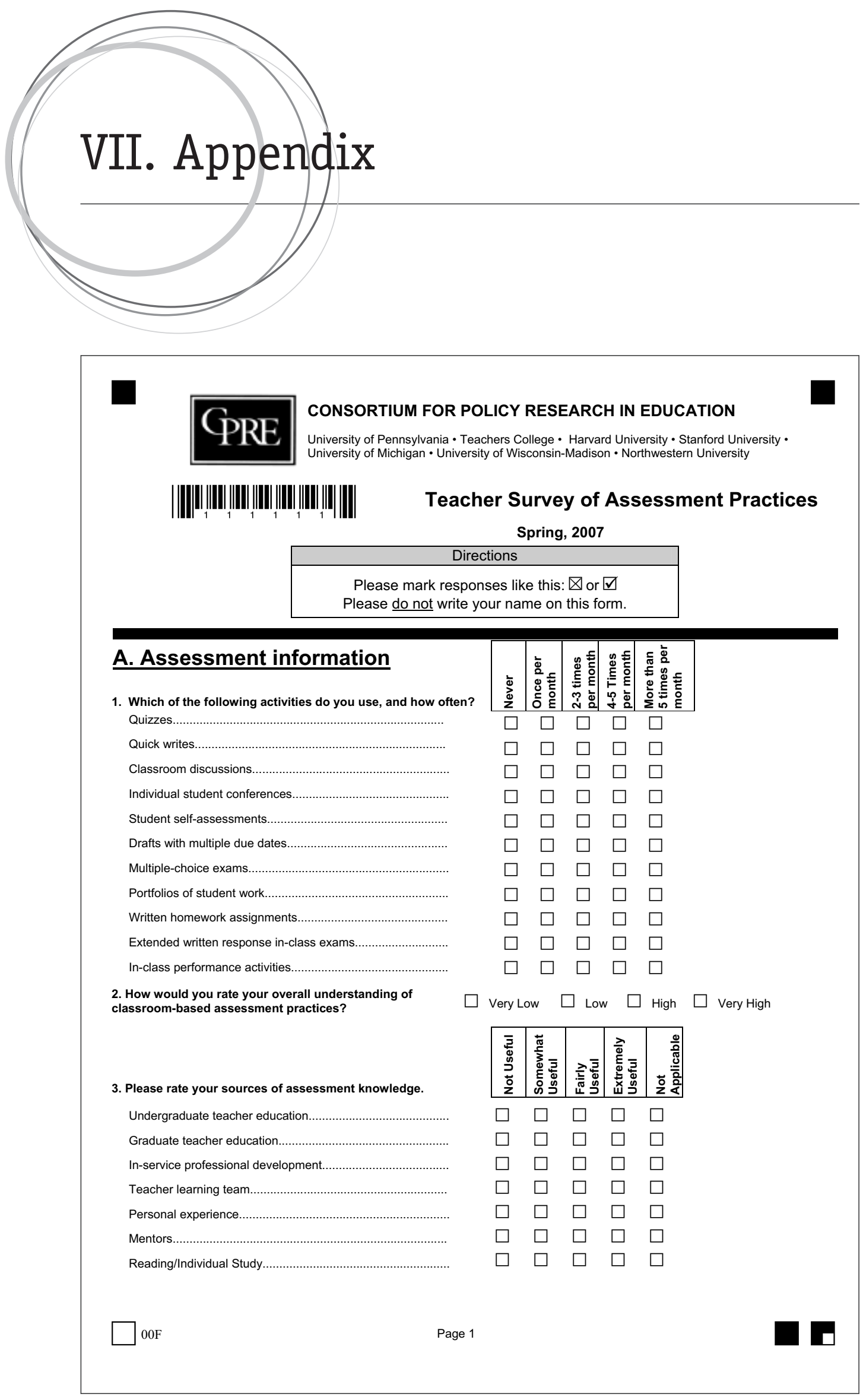


\begin{tabular}{|c|c|c|c|c|c|c|}
\hline \multirow[b]{2}{*}{$\begin{array}{l}\text { B. Assessment confidence } \\
\text { For each item listed below, please indicate your level of confidence } \\
\text { in your ability to perform the activity. In the right section, please } \\
\text { indicate whether you engage in that activity. }\end{array}$} & \multicolumn{4}{|c|}{ Level of Confidence } & \multicolumn{2}{|c|}{ Level of Use } \\
\hline & 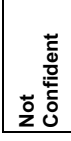 & 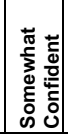 & 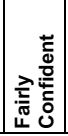 & 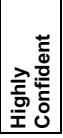 & \begin{tabular}{|c|} 
I do NOT \\
do this on \\
a regular \\
basis.
\end{tabular} & $\begin{array}{l}\text { I do this } \\
\text { on a } \\
\text { regular } \\
\text { basis. }\end{array}$ \\
\hline \multicolumn{7}{|l|}{ 1. Assessment principles } \\
\hline Using assessments to build students' desire to learn.................................. & $\square$ & $\square$ & $\square$ & $\square$ & $\square$ & $\square$ \\
\hline Using assessment results when making decisions about instruction......... & $\square$ & $\square$ & $\square$ & $\square$ & $\square$ & $\square$ \\
\hline Communicating learning goals to students in ways they can understand. & $\square$ & $\square$ & $\square$ & $\square$ & $\square$ & $\square$ \\
\hline $\begin{array}{l}\text { Translating standards into learning targets (goals/objectives/statements } \\
\text { of what we want students to know and be able to do)................................ }\end{array}$ & $\square$ & $\square$ & $\square$ & $\square$ & $\square$ & $\square$ \\
\hline $\begin{array}{l}\text { Making sure that students understand the purpose of an assessment } \\
\text { before it is conducted. }\end{array}$ & $\square$ & $\square$ & $\square$ & $\square$ & $\square$ & $\square$ \\
\hline \multicolumn{7}{|l|}{ 2. What to assess } \\
\hline Assuring that all assessments reflect clearly defined learning................... & $\square$ & $\square$ & $\square$ & $\square$ & $\square$ & $\square$ \\
\hline $\begin{array}{l}\text { Choosing the appropriate assessment method based on the learning } \\
\text { target to be assessed. }\end{array}$ & $\square$ & $\square$ & $\square$ & $\square$ & $\square$ & $\square$ \\
\hline 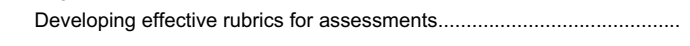 & $\square$ & $\square$ & $\square$ & $\square$ & $\square$ & $\square$ \\
\hline \multicolumn{7}{|l|}{ 3. How to assess } \\
\hline $\begin{array}{l}\text { Ensuring that no extraneous factors will get in the way of students being } \\
\text { able to show what they know. }\end{array}$ & $\square$ & $\square$ & $\square$ & $\square$ & $\square$ & $\square$ \\
\hline Making sure that I know what every test item measures................................ & $\square$ & $\square$ & $\square$ & $\square$ & $\square$ & $\square$ \\
\hline Critiquing my own assessments before I give them to students.. & $\square$ & $\square$ & $\square$ & $\square$ & $\square$ & $\square$ \\
\hline Involving students in goal setting. & $\square$ & $\square$ & $\square$ & $\square$ & $\square$ & $\square$ \\
\hline $\begin{array}{l}\text { Ensuring that the coverage of learning targets on my assessments } \\
\text { matches their relative importance during instruction.......................................... }\end{array}$ & $\square$ & $\square$ & $\square$ & $\square$ & $\square$ & $\square$ \\
\hline \multicolumn{7}{|l|}{ 4. Assessment Instruments } \\
\hline 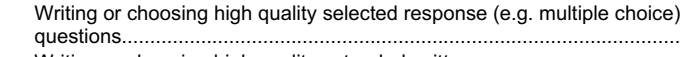 & $\square$ & $\square$ & $\square$ & $\square$ & $\square$ & $\square$ \\
\hline $\begin{array}{l}\text { Writing or choosing high quality extended written response } \\
\text { questions }\end{array}$ & $\square$ & $\square$ & $\square$ & $\square$ & $\square$ & $\square$ \\
\hline Designing high quality performance assessments... & $\square$ & $\square$ & $\square$ & $\square$ & $\square$ & $\square$ \\
\hline Orally questioning students during instruction to find out about learning. & $\square$ & $\square$ & $\square$ & $\square$ & $\square$ & $\square$ \\
\hline \multicolumn{7}{|l|}{ 5. Communicating Results and Grading } \\
\hline 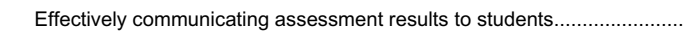 & $\square$ & $\square$ & $\square$ & $\square$ & $\square$ & $\square$ \\
\hline Effectively communicating assessment results to parents.......... & $\square$ & $\square$ & $\square$ & $\square$ & $\square$ & $\square$ \\
\hline Involving students in communicating about their own learning................. & $\square$ & $\square$ & $\square$ & $\square$ & $\square$ & $\square$ \\
\hline Providing opportunities for students to share their progress with others.. & $\square$ & $\square$ & $\square$ & $\square$ & $\square$ & $\square$ \\
\hline Providing constructive feedback to students.. & $\square$ & $\square$ & $\square$ & $\square$ & $\square$ & $\square$ \\
\hline $\begin{array}{l}\text { Developing valid grading procedures that accurately represent student } \\
\text { achievement. }\end{array}$ & $\square$ & $\square$ & $\square$ & $\square$ & $\square$ & $\square$ \\
\hline Recording the results of assessments by learning target or standard........ & $\square$ & $\square$ & $\square$ & $\square$ & $\square$ & $\square$ \\
\hline Page 2 & & & & & & \\
\hline
\end{tabular}




\begin{tabular}{|c|c|c|c|c|}
\hline $\begin{array}{l}\text { C. Assessment practice } \\
\text { For each item listed below, please indicate how frequently you engage in that activity. }\end{array}$ & 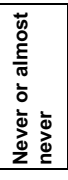 & 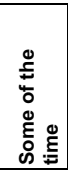 & 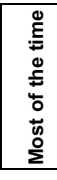 & 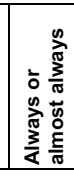 \\
\hline \multicolumn{5}{|l|}{ 1. Assessment principles } \\
\hline Assign grades to all assignments, including practice work.. & $\square$ & $\square$ & $\square$ & $\square$ \\
\hline Use assessment results to revise and guide your instruction............ & $\square$ & $\square$ & $\square$ & $\square$ \\
\hline Consider students' effort in grading assessments of achievement........... & $\square$ & $\square$ & $\square$ & $\square$ \\
\hline Use assessments to demonstrate how well students are achieving relative to one another.. & $\square$ & $\square$ & $\square$ & $\square$ \\
\hline Share anonymous comparisons among students as a way to motivate student effort.................................. & $\square$ & $\square$ & $\square$ & $\square$ \\
\hline \multicolumn{5}{|l|}{ 2. How to assess } \\
\hline 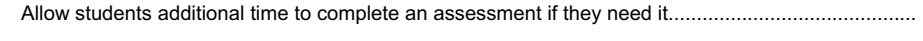 & $\square$ & $\square$ & $\square$ & $\square$ \\
\hline Assess all students with the same instrument... & $\square$ & $\square$ & $\square$ & $\square$ \\
\hline Allow students to be re-assessed, if they have not demonstrated mastery of the content.... & $\square$ & $\square$ & $\square$ & $\square$ \\
\hline Keep reading levels of test questions low unless you are assessing reading proficiencies.. & $\square$ & $\square$ & $\square$ & $\square$ \\
\hline \multicolumn{5}{|l|}{ 3. Assessment instruments } \\
\hline Ensure that all multiple choice questions on an exam have the same number of answer choices...... & $\square$ & $\square$ & $\square$ & $\square$ \\
\hline Use "all of the above" or "none of the above" as options in multiple choice test items................................... & $\square$ & $\square$ & $\square$ & $\square$ \\
\hline Use extended written response assessments to assess student reasoning........ & $\square$ & $\square$ & $\square$ & $\square$ \\
\hline Remind students of criteria by which a performance task will be judged prior to the task.... & $\square$ & $\square$ & $\square$ & $\square$ \\
\hline Ask only questions that require students to state facts... & $\square$ & $\square$ & $\square$ & $\square$ \\
\hline Prepare oral questions in advance of a lesson............................... & $\square$ & $\square$ & $\square$ & $\square$ \\
\hline Move quickly on to another student when a student fails to respond to an oral question...................... & $\square$ & $\square$ & $\square$ & $\square$ \\
\hline \multicolumn{5}{|l|}{ 4. Communicating Results and Grading } \\
\hline Limit the number of students who can receive grades of $A$................ & $\square$ & $\square$ & $\square$ & $\square$ \\
\hline Provide feedback on assessments by assigning letter grades... & $\square$ & $\square$ & $\square$ & $\square$ \\
\hline Provide descriptive feedback on assessments.. & $\square$ & $\square$ & $\square$ & $\square$ \\
\hline Involve students in tracking their progress toward learning targets... & $\square$ & $\square$ & $\square$ & $\square$ \\
\hline 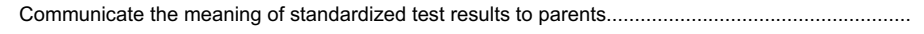 & $\square$ & $\square$ & $\square$ & $\square$ \\
\hline Communicate the meaning of standardized test results to students... & $\square$ & $\square$ & $\square$ & $\square$ \\
\hline 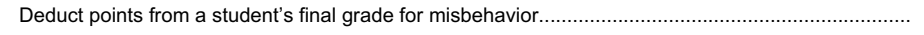 & $\square$ & $\square$ & $\square$ & $\square$ \\
\hline $\begin{array}{l}\text { Calculate report card grades that more heavily count evidence of competence at the end of a } \\
\text { grading period than at the beginning. }\end{array}$ & $\square$ & $\square$ & $\square$ & $\square$ \\
\hline Use information from parents about how their students learn in order to help plan instruction............ & $\square$ & $\square$ & $\square$ & $\square$ \\
\hline Invite parents/guardians to help interpret their students' achievement....................... & $\square$ & $\square$ & $\square$ & $\square$ \\
\hline Page 3 & & & & \\
\hline
\end{tabular}




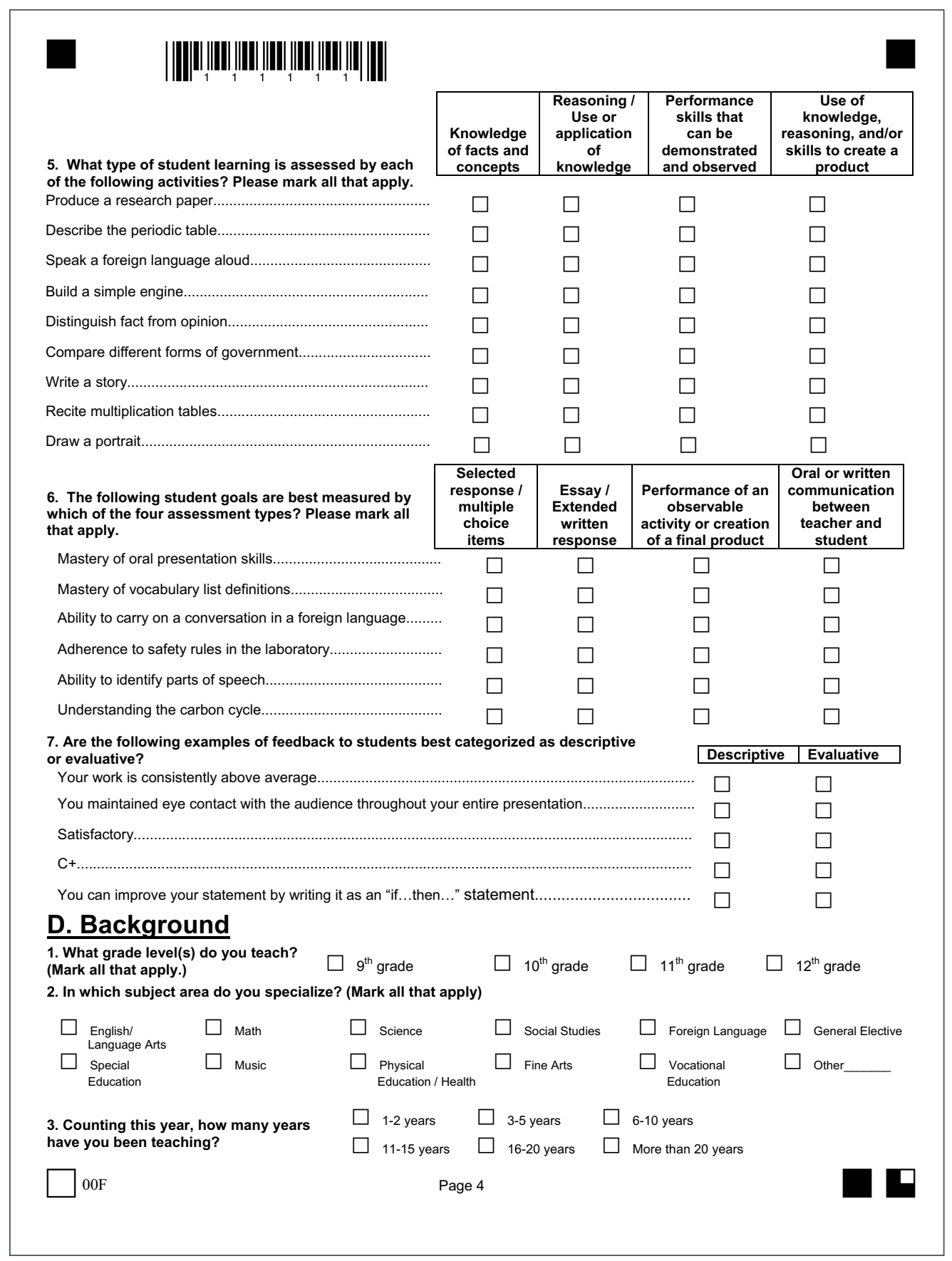




\section{About the Author}

Elliot Weinbaum is a Senior Researcher at the Consortium for Policy Research in Education (CPRE) and a Research Assistant Professor at the University of Pennsylvania. Elliot is an editor of the recently-published, The Implementation Gap: Understanding Reform in High Schools. In general, his research focuses on the development of education policy and its impact on practice and improvement at the high school and central office levels. Recent research projects and publications include a national study of high school improvement programs, a longitudinal look at the impact of state policy, and investigation of the influence of statewide accountability systems on central office function. Elliot holds a Ph.D. in Education Policy from the University of Pennsylvania.

\section{Select CPRE Publications}

Below is a list of recent CPRE policy briefs and research reports. Visit CPRE's web site www.cpre.org to download free copies and to search our extensive inventory of publications featuring research on a variety of education topics including accountability, teacher quality and compensation, school finance, instructional improvement, international education projects, and much more.

\section{Policy Briefs}

A Comparative Study of Teacher Preparation and Qualifications in Six Nations. Richard M. Ingersoll, CPRE Policy Brief (RB-47), February 2007.

Misdiagnosing the Teacher Quality Problem. Richard M. Ingersoll, CPRE Policy Brief (RB-49), February 2007.

Redesigning School Finance Systems: Lessons from CPRE Research. Allan Odden, CPRE Policy Brief (RB-50), February 2007.

Teacher Performance Pay: Synthesis of Plans, Research, and Guidelines for Practice. Herbert Heneman III, Anthony Milanowski, and Steven Kimball, CPRE Policy Brief (RB-46), February 2007.

Teaching Matters: How State and Local Policymakers Can Improve the Quality of Teachers and Teaching. Thomas B. Corcoran, CPRE Policy Brief (RB-48), February 2007.

\section{Research Reports}

A Formative Study of the Implementation of the Inquiry Team Process in New York City Public Schools: 2007-08 Findings. Marian Robinson, Patricia, Kannapel, Joan Gujarati, Hakim Williams, and Andrea Oettinger, CPRE Research Report (RR-60), 2008.

The Inquiry Based Science and Technology Education Program (IN-STEP): The Evaluation of the First Year. Thomas B. Corcoran. CPRE Research Report (RR-59), May 2008.

A Randomized Evaluation of Ohio's Personalized Assessment Reporting System (PARS). Henry May and Marian Robinson, CPRE Research Report (RR-58), December 2007.

A Comparative Study of Teacher Preparation and Qualifications in Six Nations. Richard M. Ingersoll (Ed.), CPRE Research Report (RR-57), 2007.

Holding High Hopes: How High Schools Respond to State Accountability Policies. Betheny Gross and Margaret Goertz (Eds.), CPRE Research Report (RR-56), June 2005. 
Learning About Assessment: An Evaluation of a Ten-State Effort to Build Assessment Capacity in High Schools 
GRE 